\title{
Analysing the Role of Crowdfunding in Entrepreneurial Ecosystems \\ A Social Media Event Study of Two Competing Product Launches
}

Menon, Karan; Kärkkäinen, Hannu ; Jussila, Jari; Huhtamäki, Jukka; Mukkamala, Raghava Rao; Lasrado, Lester Allan ; Vatrapu, Ravi; Hussain, Abid

Document Version

Accepted author manuscript

Published in:

International Journal of Entrepreneurship and Small Business

DOI:

10.1504/IJESB.2018.090363

Publication date:

2018

License

Unspecified

Citation for published version (APA):

Menon, K., Kärkkäinen, H., Jussila, J., Huhtamäki, J., Mukkamala, R. R., Lasrado, L. A., Vatrapu, R., \& Hussain, A. (2018). Analysing the Role of Crowdfunding in Entrepreneurial Ecosystems: A Social Media Event Study of Two Competing Product Launches. International Journal of Entrepreneurship and Small Business, 33(4), 575606. https://doi.org/10.1504/IJESB.2018.090363

Link to publication in CBS Research Portal

\section{General rights}

Copyright and moral rights for the publications made accessible in the public portal are retained by the authors and/or other copyright owners and it is a condition of accessing publications that users recognise and abide by the legal requirements associated with these rights.

\section{Take down policy}

If you believe that this document breaches copyright please contact us (research.lib@cbs.dk) providing details, and we will remove access to the work immediately and investigate your claim. 


\section{Analysing the Role of Crowdfunding in Entrepreneurial Ecosystems: A Social Media Event Study of Two Competing Product Launches}

\section{Karan Menon, Hannu Kärkkäinen, Jari Jussila, Jukka Huhtamäki, Raghava Rao Mukkamala, Lester Allan Lasrado, Ravi Vatrapu, and Abid Hussain}

Journal article (Accepted manuscript*)

\section{Please cite this article as:}

Menon, K., Kärkkäinen, H., Jussila, J., Huhtamäki, J., Mukkamala, R. R., Lasrado, L. A., ... Hussain, A. (2018). Analysing the Role of Crowdfunding in Entrepreneurial Ecosystems: A Social Media Event Study of Two Competing Product Launches. International Journal of Entrepreneurship and Small Business, 334), 575-606. https://doi.org/10.1504/IJESB.2018.090363

DOI: https://doi.org/10.1504/IJESB.2018.090363

* This version of the article has been accepted for publication and undergone full peer review but has not been through the copyediting, typesetting, pagination and proofreading process, which may lead to differences between this version and the publisher's final version AKA Version of Record.

Uploaded to CBS Research Portal: September २०19 


\title{
Analysing the Role of Crowdfunding in Entrepreneurial Ecosystems: A Social Media Event Study of Two Competing Product Launches
}

\author{
Karan Menon*, Hannu Kärkkäinen, Jari \\ Jussila and Jukka Huhtamäki \\ Tampere University of Technology, PL541, 33101 Tampere, Finland \\ E-mail: karan.menon@tut.fi \\ E-mail: hannu.karkkainen@tut.fi \\ E-mail: jari.j.jussila@tut.fi \\ E-mail: jukka.huhtamaki@tut.fi \\ *Corresponding author
}

\section{Raghava Rao Mukkamala}

Copenhagen Business School, Howitzvej 602000 Frederiksberg, Denmark

and

Westerdals Oslo School of ACT, Christian Krohgs gate 32, 0186, Oslo,

Norway

E-mail: rrm.digi@cbs.dk

\section{Lester Allan Lasrado}

Copenhagen Business School, Howitzvej 602000 Frederiksberg, Denmark

E-mail: lal.digi@cbs.dk

\section{Ravi Vatrapu}

Copenhagen Business School, Howitzvej 602000 Frederiksberg, Denmark

and

Westerdals Oslo School of ACT, Christian Krohgs gate 32, 0186, Oslo, Norway

E-mail: rv.digi@cbs.dk

\section{Abid Hussain}

Copenhagen Business School, Howitzvej 602000 Frederiksberg,

Denmark

E-mail: ah.digi@cbs.dk 


\title{
Menon et al.
}

\begin{abstract}
The aim of the explorative study is to understand the role of crowdfunding in the facilitation of customer engagement for entrepreneurial ecosystems, using data from two recent events of competing product launches. We conducted an event study that employed content analysis and emotion analysis, as well as social set analysis (SSA) of Facebook data to uncover and better understand crowdfunder (investor and customer) engagement and interactions before, during and after a crowdfunding campaign event. Our paper focuses especially on the role of Jolla's tablet crowdfunding campaign in the development of its fanbase in relation with Nokia's tablet launch during Slush 2014 event. On the basis of the above analyses and related literature, we present propositions about various types of engagement with the potential to facilitate the evolution of entrepreneurial ecosystems. We discuss the results, and evaluate the implications of crowdfunding on customer engagement for entrepreneurial ecosystems, and conclude with directions for future work. One of the key contributions of the study is the introduction of a new data source and approach for co-creative interaction between companies and their customers, as well as an approach to support the study of ecosystems from a customer perspective.
\end{abstract}

Keywords: Social Media, Crowdfunding, Social Set Analysis, Entrepreneurship, Ecosystem, Visual Analytics, Text Analytics, Emotion Analysis, Purchase Decision Making

Reference to this paper should be made as follows: Author. (xxxx) 'Title', Int. J. $x x x x x x x x x x x x x \times x x x x x x x x x x x$,

Biographical notes: Karan Menon, B.Eng., M.Sc. (Tech.) is a PhD Fellow at DARE Business Data Research Group \& Novi Research Center, Laboratory of Industrial and Information Management at Tampere University of Technology, Tampere, Finland. His research is currently focused on industrial internet/industry 4.0, information systems, social network analysis, big social data and crowdfunding. He is the recipient of a one year full-time grant from Finnish Cultural Foundation for his Doctoral work.

Hannu Kärkkäinen is Professor of Knowledge Management at DARE Business Data Research Group \& Novi Research Center, Laboratory of Industrial and Information Management at Tampere University of Technology, Tampere, Finland. His current research interests include knowledge management and decision making in innovation, organizational learning, customer needs assessment in business-to-business organizations, and co-operation and value networks in innovation. Social media and big social data analytics are currently some of his focal research interests, as they bring new important possibilities to the above generic topics. He has published a number of refereed international journal articles in journals like Computers in Human Behavior, R\&D Management and International Journal of Production Economics, as well as several books and other publications, on the above topics.

Jari Jussila, B.Eng., M.Sc., D.Sc. is a Postdoctoral Researcher at DARE Business Data Research Group \& Novi Research Center, Laboratory of Industrial and Information Management at Tampere University of Technology, Tampere, Finland. He completed his doctoral thesis on social media use in business-to-business companies' innovation. His research is currently focused on social media, crowdsourcing, as well as, big social data analytics.

Jukka Huhtamäki, M.Sc., D.Sc. (Tech) is a Postdoctoral Researcher at DARE Business Data Research Group \& Novi Research Center, Laboratory of Industrial and Information Management at Tampere University of Technology, 
Analysing the Role of Crowdfunding in Entrepreneurial Ecosystems: A Social Media Event Study of Two Competing Product Launches

Tampere, Finland and a founding member of the Innovation Ecosystems Network. Jukka is developing computational methods for investigating digital ecosystems, including platform-based ecosystems, API ecosystems, and other types of business and innovation ecosystems that have a digital dimension. $\mathrm{He}$ is an Associate Editor of Behaviormetrika and has published a number of articles and scientific book chapters taking a computational approach to investigations in several domains, including business, innovation, and communication studies.

Raghava Mukkamala is an Associate Professor at the Department of Digitalization, Copenhagen Business School; Associate Professor of applied computing at the Westerdals Oslo School of Arts Communication and Technology. Raghava's current research focus is on interdisciplinary approach to big data analytics. Combining formal/mathematical modeling approaches with data/text mining techniques and machine learning methodologies, his current research program seeks to develop new algorithms and techniques for big data analytics such as Social Set Analytics. Raghava holds a PhD degree in Computer Science and a M.Sc degree in Information Technology, both from IT University of Copenhagen, Denmark and a Bachelor of Technology degree from Jawaharlal Nehru Technological University, India. Before moving to research, Raghava has many of years of programming and IT development experience from Danish IT industry.

Lester Allan Lasrado, B.Eng., M.Sc. (Tech.) is a PhD Fellow at the Department of Digitalization of the Copenhagen Business School, Denmark. His research interests include studying Maturity Models in Information Systems, exploring the potential of alternative methods like Qualitative Comparative Analysis (QCA) and Necessary Condition Analysis (NCA), Visual Analytics and Crowdfunding. Lester's $\mathrm{PhD}$ focuses on formalising and applying set theoretic thinking for designing maturity models. Lester also teaches social media management and visual analytics at Copenhagen Business School and has supervised master thesis' on topics including Social CRM, Maturity Models and Big Data.

Ravi Vatrapu is a professor of business data analytics at the Department of Digitalization of the Copenhagen Business School, professor of applied computing at the Westerdals Oslo School of Arts, Communication and Technology, and director of the Centre for Business Data Analytics (bda.cbs.dk). Prof. Vatrapu and his research group focus on big social data analytics and are developing a novel approach to computational social science called Social Set Analysis based on the enactive approach to the philosophy of mind, phenomenological approach to sociology, and the mathematics of classical, fuzzy and rough set theories. Social Set Analysis seeks to design, develop and evaluate in terms of fundamentally novel formal models, predictive methods and visual analytics tools for big social data.

Abid Hussain is an assistant professor of business data analytics at the Department of Digitalization of the Copenhagen Business School, Denmark. His primary research interest seeks to develop methods, techniques and models to retrieve, store, process and analyze very large sets of data streams. He holds a $\mathrm{PhD}$ degree in Information Systems that contributed design proposition, patterns and principles for Big Social Data Analytics and Big Social Data Analytics Tool (SODATO) is also product of his $\mathrm{PhD}$ work. His current research focus is on extracting meaningful insights by combining organizational in-house business data with Big Social Data.Abid holds an M.Sc. Degree in Computer Sciences and has worked in IT industry for many 


\begin{abstract}
Menon et al.
years in diverse technical and managerial roles as senior programmer, lead system architect and team lead. He has intensive experience in the area of data sharing, integrations and security for medium to large scale enterprise solutions.

This paper is a revised and expanded version of a paper entitled Crowdfunding in the development of social media fanbase - case study of two competing ecosystems presented at 49th Hawaii International Conference on System Sciences (HICSS), Hawaii Jan $5^{\text {th }}$ to $8^{\text {th }} 2016$.
\end{abstract}

\title{
1 Introduction
}

Various types of ecosystems involve a heterogeneous and continuously evolving set of entities that are interconnected through a complex, global network of relationships (Huhtamäki et al., 2015). Firms in ecosystems come from a variety of market segments, each providing their own unique value propositions (Jussila et al., 2016). The value creation and appropriation require orchestration between these firms across segments (Belleflamme et al., 2014). In the mobile ecosystem, for instance, the value for the users of tablets is co-created by integration of tablet designers and manufacturers, accessory makers, mobile network operators, operating systems and applications. Co-creation is an essential ecosystem characteristic, because a continual realignment of synergistic relationships of resources is required for the growth of the system and responsiveness to changing internal and external forces (Rubens et al., 2011).

Crowdfunding is a new approach for supporting and funding the development of startups, entrepreneurs, and ecosystems in general. Crowdfunding can be used e.g. for identifying and involving new consumers, customers, and both individual and professional funders to ecosystems (Beier and Wagner, 2017; Wu et al., 2015). Compared to traditional product launch crowdfunding supports all the steps of consumer decision making process from viewing product advertisement to product purchase or pre-purchase (Erkinheimo et al., 2016; Lavidge and Steiner, 1961). Crowdfunding provides the means to launch products that are in development phase, but available for consumers for prepurchase. In addition, crowdfunding campaigns can be used as leverage to attract angel and institutional investors to invest in start-ups and new ecosystem players (Erkinheimo et al., 2016). Crowdfunding can also facilitate various different types of value cocreation between actors joined together with a crowdfunding platform and initiative (Quero et al., 2014), and makes possible the formation of new types of service and valueexchange ecosystems (Vargo et al., 2015).

The aim of this explorative study is to understand the role of crowdfunding in the facilitation of customer engagement and entrepreneurial ecosystems. The specific research question this paper addresses is: what, if any, is the role and potential impact of crowdfunding campaigns on the development of customer engagement for companies and their entrepreneurial ecosystems? The impact of crowdfunding is explored in terms of the interactions, brand associations, emotions, and stages of consumer behavior that can be inferred from Facebook actions. 
Analysing the Role of Crowdfunding in Entrepreneurial Ecosystems: A Social Media Event Study of Two Competing Product Launches

The remainder of the paper is organized as follows. Section 2 presents and discusses relevant theories and concepts in crowdfunding and business ecosystems. Section 3 presents methodological details on the case study in terms of case selection criteria, social data collection, data processing, data analysis etc. Findings are reported in Section 4 with their substantive discussion in Section 5 together with propositions derived from the case study, limitations and future research directions.

\section{Exploring research in Crowdfunding}

\subsection{Crowdfunding - Definition and State of the Art}

Crowdfunding via the internet is a relatively recent phenomenon in research and is now gathering momentum (Belleflamme et al., 2014). However, broadly speaking, the overall concept has been around for centuries individuals or institutions raising money from people for elections, wars, social causes and micro financing much before the formation of crowdfunding intermediaries (Lasrado and Lugmayr, 2013). Crowdfunding can be seen as a subset of crowdsourcing (Bretschneider et al., 2014; Lasrado and Lugmayr, 2013; Mollick, 2014; Zheng et al., 2014), with an extra feature of generating finances for the proposed idea or initiative. There are many definitions and perspectives of crowdfunding proposed in recent literature, however we adopt the one by (Lasrado and Lugmayr, 2013), and define it as a "process of an individual or group of individuals or institutions raising capital for a cause; be it cultural, social or business by attracting small contributions from a large crowd by using social media and internet as the medium for communication". Crowdfunding is a complex phenomenon, given the number of elements involved and after reviewing recent extant literature we arrive at six core elements (Huhtamäki et al., 2015):

1. Crowd - refers to large group or conglomeration of individuals contributing via the internet, by financially supporting a project or cause (Lasrado and Lugmayr, 2013).

2. Project owners - are project creators or entrepreneurs seeking capital (Belleflamme et al., 2014; Fisk et al., 2011).

3. Intermediaries - are crowdfunding platforms (CFP) i.e. a virtual hub for the crowd and project owners (Belleflamme et al., 2014). E.g. Indiegogo, Kickstarter, Invesdor, etc.

4. Funding Mechanism - are the principles or rules the intermediaries set under which funding takes place (Schulz et al., 2015). E.g. All-or-nothing (AON) setting i.e. projects only receives funds when minimum amount is raised, keep it all (KIA) funding approach i.e. project owners can decide to keep the funds even if targets are not met.

5. Specialization - refers to type of projects the intermediaries support (Schulz et al., 2015). Kickstarter and Indiegogo support projects, while equity crowdfunding platforms support startups or business. E.g. Innovestment or Invesdor.

6. Return Type - is the return of investment or incentives for the crowd (Lasrado and Lugmayr, 2013). E.g. Goodwill or thank you for donations, some form of tangible 
Menon et al.

rewards i.e. products or financial return for reward and equity crowdfunding respectively.

These six core elements can help researchers to analyze and study crowdfunding. The configuration of these six elements combined with participation intent of the crowd investors i.e. active or passive and return of investment expected, one could classify crowdfunding models into 4 broad categories (Lasrado, 2013), i.e. reward, donation, lending \& equity as shown in figure 1.

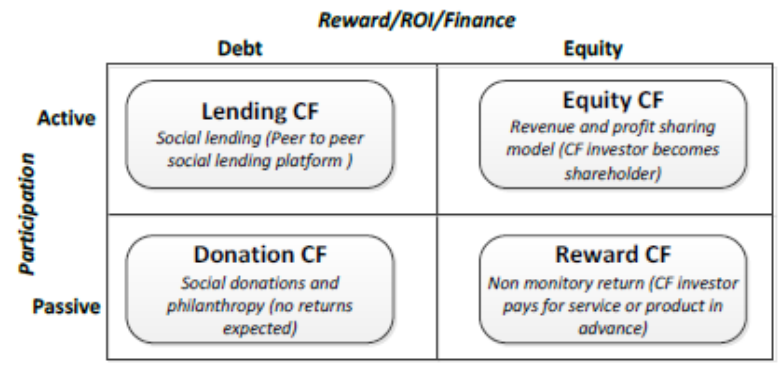

Figure 1: Crowdfunding project types (Huhtamäki et al., 2015; Lasrado, 2013).

The classification is now widely accepted by researchers and crowdfunding platforms alike, thus allowing positioning of these platforms in general and research in particular. The application of this categorization is shown in table 1, wherein we differentiate crowdfunding platforms we came across in our literature review. This is an important step, as it would facilitate cross project or platform comparison while studying attributes of crowdfunding, especially while using large datasets (Huhtamäki et al., 2015).

Table 1: Differentiating Crowdfunding platforms (Huhtamäki et al., 2015).

\begin{tabular}{l|l|l|l}
\hline Platform & FM & Project Type & Restrictions \\
\hline Indiegogo (USA) & $\begin{array}{l}\text { AON } \\
\text { KIA }\end{array}$ & $\begin{array}{l}\text { Reward } \\
\text { Donation }\end{array}$ & None, it is international \\
\hline Kickstarter (USA) & AON & Only Reward & Project creators restricted* \\
\hline $\begin{array}{l}\text { Innovestment } \\
\text { (Germany) }\end{array}$ & AON & Only Equity & Only technology startups ** \\
\hline \begin{tabular}{l} 
Invesdor (Finland) \\
\hline
\end{tabular} & AON & Only Equity & Minimum goal is $€ 20,000$ \\
\hline
\end{tabular}

*Nationals of US, Australia, New Zealand, UK and selected EU countries.

** Restricted to German nationals, both startups and investors.

FM - Funding mechanism; AON- All or Nothing; KIA - Keep it all

A large number of crowdfunding platforms have emerged across the four categories, however research on crowdfunding platforms has been largely neglected (Haas et al., 2014). Research published before the year 2014 on crowdfunding has mostly focused on reward-based crowdfunding with equity based crowdfunding investigated only by very few researchers e.g. (Belleflamme et al., 2014; Bretschneider et al., 2014).

In recent years the focus of crowdfunding studies seem to have shifted from qualitative case studies approach to extensive explorative quantitative studies (Huhtamäki et al., 2015). Therefore, in the next section we present our literature review of the studies on 
Analysing the Role of Crowdfunding in Entrepreneurial Ecosystems: A Social Media Event Study of Two Competing Product Launches

crowdfunding using large datasets while primarily focusing on the techniques applied and their contributions to research.

\subsection{State of Quantitative Research in Crowdfunding}

As argued in our previous papers (Huhtamäki et al., 2015; Jussila et al., 2016), Crowdfunding research has been gaining momentum and the number of publications has been steadily rising. Table 2 showcases recent examples of research perspectives when it comes to crowdfunding. The research approach seems to have moved from qualitative case study approach e.g. (De Buysere et al., 2012; Fisk et al., 2011; Lasrado and Lugmayr, 2013) to extensive explorative quantitative analysis e.g. (Belleflamme et al., 2014; Mollick, 2012) given the increased maturity of data crawling algorithms, access to rich datasets and willingness of platforms to share data. The year 2014 and 2015 have seen a significant number of data driven publications, specially using dataset from crowdfunding platform Kickstarter ${ }^{1}$ and a handful from other platforms including a couple of papers using Indiegogo ${ }^{2}$ (Huhtamäki et al., 2015).

Table 2: Data driven research on Crowdfunding (Huhtamäki et al., 2015; Jussila et al., 2016).

\begin{tabular}{|c|c|c|c|c|c|}
\hline Authors & \multicolumn{2}{|c|}{ DC } & \multicolumn{2}{|c|}{ M\&A } & Comments \& Findings \\
\hline $\begin{array}{l}\text { (Cumming et } \\
\text { al., 2014) }\end{array}$ & $\mathrm{WC}$ & $\mathrm{CF}$ & VA & TA & $\begin{array}{l}\text { Automated Readability indexes computed to } \\
\text { use readability of project description, which } \\
\text { is in turn used a variable. } \\
\text { AON has more success than KIA, both with } \\
\text { credibility \& raising funds. }\end{array}$ \\
\hline $\begin{array}{l}\text { (Thies et al., } \\
\text { 2014) }\end{array}$ & $\mathrm{WC}$ & $\begin{array}{l}\text { CF } \\
\text { SM }\end{array}$ & VA & ---- & $\begin{array}{l}\text { Collected data from Indiegogo, Twitter, } \\
\text { Facebook- Identified positive influence of } \\
\text { social buzz and Facebook shares as factors } \\
\text { for crowdfunding project success. }\end{array}$ \\
\hline $\begin{array}{l}\text { (Posegga et al., } \\
2015)\end{array}$ & $\mathrm{WC}$ & $\mathrm{CF}$ & NA & ---- & $\begin{array}{l}\text { Project creators use multiple accounts to } \\
\text { hide previous failures, while backing other } \\
\text { projects. Females receive more support, } \\
\text { while males support female actors more. }\end{array}$ \\
\hline $\begin{array}{l}\text { (Frydrych et } \\
\text { al., 2014) }\end{array}$ & $\mathrm{WC}$ & $\mathrm{CF}$ & $\mathrm{DE}$ & ---- & $\begin{array}{l}\text { Also found that women experience a higher } \\
\text { success rate than males. }\end{array}$ \\
\hline $\begin{array}{l}\text { (Müllerleile } \\
\text { and Joenssen, } \\
2015)\end{array}$ & $\mathrm{WC}$ & $\mathrm{CF}$ & VA & EM & $\begin{array}{l}\text { Word count in the project description used } \\
\text { as a variable with percentage of positive and } \\
\text { negative emotion words such as love, nice, }\end{array}$ \\
\hline
\end{tabular}

\footnotetext{
${ }^{1}$ Kickstarter is for creative projects, launched in 2009, has raised over $\$ 1.5$ billion with over 8 million donors, and 80,000 projects. Kickstarter does not allow fundraising for charity and equity crowdfunding.

2 Launched in 2008, Indiegogo has become the second largest crowdfunding platform worldwide (approx. 60,000 projects).
} 
Menon et al.

\begin{tabular}{|c|c|c|c|c|c|}
\hline & & & & & $\begin{array}{l}\text { nice, hurt, hate and nervous checked for. A } \\
\text { very simplistic approach to emotion analysis } \\
\text { applied. } \\
\text { Projects that do not have their own website } \\
\text { or social media presence are more likely to } \\
\text { fail. }\end{array}$ \\
\hline $\begin{array}{l}\text { (Greenberg } \\
\text { and Gerber, } \\
\text { 2014) }\end{array}$ & WC & $\begin{array}{l}\text { CF } \\
\text { SM }\end{array}$ & VA & ---- & $\begin{array}{l}\text { Mixed-methods approach - WC supported } \\
\text { by interviews from } 11 \text { failed project } \\
\text { creators. Social media data, especially } \\
\text { number of friends connected via Facebook } \\
\text { and followers via Twitter used as a variable. } \\
\text { People who relaunch their failed campaigns } \\
\text { succeed } 43 \% \text { of the time, while learning } \\
\text { from previous mistakes. }\end{array}$ \\
\hline$\left(\begin{array}{l}\text { (An } \\
2014)\end{array}\right.$ & WC & $\begin{array}{l}\text { CF } \\
\text { SM }\end{array}$ & $\mathrm{DE}$ & ---- & $\begin{array}{l}\text { WC from Kickstarter and Twitter. Found } \\
\text { evidence that frequent investors are attracted } \\
\text { by ambitious projects, while occasional ones } \\
\text { act as donors mostly for art projects. }\end{array}$ \\
\hline $\begin{array}{l}\text { (Zvilichovsky } \\
\text { et al., 2014) }\end{array}$ & WC & $\mathrm{CF}$ & VA & ---- & $\begin{array}{l}\text { Project creators who have backed others in } \\
\text { the past have higher success rates. }\end{array}$ \\
\hline $\begin{array}{l}\text { (Mollick, } \\
\text { 2012) }\end{array}$ & WC & $\mathrm{CF}$ & VA & ---- & $\begin{array}{l}\text { One of first studies on Crowdfunding using } \\
\text { crawled dataset. The studies found that vast } \\
\text { majority of project creators deliver their } \\
\text { promise post the campaign, however only } \\
25 \% \text { of them make it on time. }\end{array}$ \\
\hline $\begin{array}{l}\text { (Zheng et al., } \\
\text { 2014) }\end{array}$ & $M$ & SU & VA & ---- & $\begin{array}{l}\text { Survey of the investors/donors revealed that } \\
\text { project difficulty reduces the } \\
\text { implementation success, while team } \\
\text { experience is critical to crowdfunding } \\
\text { project success. }\end{array}$ \\
\hline $\begin{array}{l}\text { (Schulz et al., } \\
\text { 2015) }\end{array}$ & $M$ & $\mathrm{CF}$ & VA & --- & $\begin{array}{l}\text { Purposeful sampling of } 108 \text { crowdfunding } \\
\text { projects from } 20 \text { platforms; Empirically } \\
\text { proved a positive impact of idea creativity } \\
\text { and hedonic value on the success of a } \\
\text { campaign depending on the type of } \\
\text { crowdfunding. }\end{array}$ \\
\hline
\end{tabular}

Table 2 highlights the contributions of data driven approach to research on crowdfunding using datasets that are extensive, reliable and very impressive. Recent contributions have also analyzed specific crowdfunding process challenges (Schulz et al., 2015; Zheng et al., 2014) and also looked at motivations for participation in crowdfunding (Bretschneider et 
Analysing the Role of Crowdfunding in Entrepreneurial Ecosystems: A Social Media Event Study of Two Competing Product Launches

al., 2014; Feldmann et al., 2014; Gierczak et al., 2014). Table 2 mostly highlights the contributions of data driven approach to research on crowdfunding using datasets that are extensive, reliable and very impressive both from Crowdfunding platforms themselves and also from other social media platforms from Twitter and Facebook, thus highlighting impact of social media on Crowdfunding success (Huhtamäki et al., 2015; Jussila et al., 2016).

However, from our detailed review of prior literature of crowdfunding literature, first, no previous studies have made to study the impact of crowdfunding on an organization's social media presence. Secondly, we found no studies that have used two or more cases using social media data (Facebook in our case) to study the impact of crowdfunding. Third, we found none of the studies using well established automated text analysis techniques (e.g. emotion analysis or sentiment analysis) to study the impact of crowdfunding. This is surprising since emotions have been found to trigger greater impact on buying decisions. (Adelaar et al., 2003)

\subsection{Roles of Crowdfunding in Entrepreneurship and Ecosystems}

Both reward-based and equity based crowdfunding are important vehicles for entrepreneurs, as finding sufficient financial resources is one of the most challenging tasks facing an entrepreneur (Hisricha et al., 2005). Furthermore, crowdfunding can be used to increase customers' awareness and knowledge of the product of the company, ultimately moving the customers towards purchase or pre-purchase of the product (in more detail, see section 2.4).

The ecosystem concept is rooted in biology. According to (Moran, 1990), "ecosystem generally refers to the structural and functional interrelationships among living organism and the physical environment within which they exist."

(Moore, 1993) first introduced the concept in the business literature in his seminal article on business ecosystems. The article discusses new ways for a company to allow other companies to create value for them, that is, to the focal company of a business ecosystem. The main rationale for the introduction of the ecosystem concept is the increasingly interconnected nature of value creation (Adner and Kapoor, 2010; Iansiti and Levien, 2004). The value creation is taking place outside and in-between companies and other organizations, that is, in ecosystems. Ecosystems are dynamic by nature: co-evolution, co-creation, and co-opetition are all temporal mechanisms. Most importantly, no individual actor, be it company, organization, governmental entity, or individual person, is able to manage an ecosystem. Therefore, ecosystems are rather orchestrated than managed (Ritala and Hurmelinna-Laukkanen, 2013, 2009; Russell et al., 2015)

Recently, four key branches of ecosystem literature have been identified (Thomas et al., 2017; Valkokari, 2015). In addition to business ecosystems (Moore, 1993), innovation ecosystems (Adner and Kapoor, 2010; Russell et al., 2011), knowledge ecosystems (Clarysse et al., 2014), and entrepreneurial ecosystems receive attention from scholars. Platforms are a central piece of business ecosystems and the most important individual mechanism in platforms is leverage: "leverage refers to a process of generating an impact that is disproportionately larger than the input required" (Autio and Thomas, 2014). Platform ecosystems combine aspect of all three rational for leverage: production, innovation, and transaction (Thomas et al., 2014). 
Menon et al.

(Autio and Thomas, 2014) define the innovation ecosystem as "a network of interconnected organizations, organized around a focal firm or a platform, and incorporating both production and use side participants, and focusing on the development of new value through innovation." Moreover, innovation ecosystems function as an integrating mechanism that allows both for the exploration of new knowledge and the exploitation of existing knowledge in a recombinant manner (Valkokari, 2015). Companies in an innovation ecosystem are "loosely interconnected" (Iansiti and Levien, 2004), that is, the success of a given innovation often relies on the success the environment of the focal company that allows for the success of those that develop complementary products and services. Indeed, (Iansiti and Levien, 2004) point to the role of complementary product developers and customers among key actors in business ecosystems: "makers of complementary products that are used in conjunction with your own. It even includes competitors and customers, when their actions and feedback affect the development of your own products or processes."

Entrepreneurial activities are often studied under innovation ecosystems. (Russell et al., 2015) define use the innovation ecosystem concept to refer "to the inter-organizational, political, economic, environ- mental, and technological systems through which a milieu conducive to business growth is catalyzed, sustained, and supported." They further note, "A dynamic innovation ecosystem is characterized by a continual realignment of synergistic relationships that promote growth of the system." Importantly, (Russell et al., $2015,2011)$ include venture capital investors and individual persons as key actors in innovation ecosystems. (Thomas et al., 2017) note, "organizations seldom operate in perfectly competitive markets characterized by arms-length transactions and head-to-head competition between firms producing substitutable products, but rather, in network structures composed by co-specialized organizations that play complementary roles to cocreate value." (Thomas et al., 2017) further describe the ecosystemic context of new company creation: "startups emerge and grow not only because of heroic, talented and visionary individuals (entrepreneurs), but also because the startups are located in a network of private and public players which nurture and sustain them." (Autio, 2015) elaborates, "entrepreneurial ecosystems allocate resources to productive uses through the creation (or not) of innovative and high-growth new ventures."

We see that crowdfunding has implications in all three ecosystem domains, business, innovation, and entrepreneurial.

First, crowdfunding extends the market mechanism to products and services that are not yet part of companies' offering. This allows consumers to express and interest in new offerings and even prioritize their development. Moreover, crowdfunding introduces a mechanism for the focal company to invite developers or complementarities to introduce their offering and collect funding and conduct co-creation. We consider this value creation to take place in the innovation ecosystems realm.

Second, crowdfunding is a completely new way to fund the development of products and services. In other words, crowdfunding can be considered a new entrepreneurial ecosystem instrument supporting seed funding for new companies as well as a source of investment for companies developing new products and services.

Finally, it is important to realize that crowdfunding itself is an application of platformbased business ecosystem giving leverage to through a multi-sided market of companies running campaigns for themselves and their complementors, addressing potential customers and consumers, some of which are also part of the business ecosystem of the crowdfunding platform. 
Analysing the Role of Crowdfunding in Entrepreneurial Ecosystems: A Social Media Event Study of Two Competing Product Launches

\subsection{Crowdfunding and customer engagement}

Crowdfunding has many benefits related to new funding mechanisms and changing the risk profile of SMEs, start-ups and entrepreneurs (see e.g. (Greenberg and Gerber, 2014; Macht and Weatherston, 2014)), which have been studied relatively widely already. However, a very little studied aspect of crowdfunding, especially from quantitative empirical perspective, is its potential to impact and reshape the focal customer- seller relationship (Bitterl and Schreier, 2016), for instance the extent to which crowdfunding participants can personally connect to and identify with the companies making use of crowdfunding or their crowdfunded products. The studies of (Fisk et al., 2011; Gerber et al., 2012)demonstrate, through qualitative (not quantitative as in our case) studies, that the themes of "feelings of connectedness" and "a strong sense of belongingness," emerged for participants in crowdfunding projects toward crowdfunded products and related companies. In addition, recent literature has also preliminarily demonstrated that social networks have an important role in motivating crowdfunding investment decisions (e.g. (Herkman and Brussee, 2012; Lu et al., 2014)). This paper contributes to the existing crowdfunding literature by empirically studying customer engagement contrasting the quantitative empirical analysis of a company that went through the process of crowdfunding to another company, in the similar domain, that went through the traditional sales process of releasing a product and selling through retailers to the end customers, while also employing emotion analysis techniques.

Furthermore, few previous qualitative crowdfunding studies (e.g. (Berndt and Mbassana, 2016; Rodrigues, 2015) have, for instance applied the hierarchy of effects model proposed by (Ray et al., 1973), or a more detailed one proposed by (Lavidge and Steiner, 1961), which measure consumer decision making process stages that the consumers follow on the way from viewing an advertisement to the purchase of a product. We are not aware of existing previous quantitative studies in this vein of research. In the above studies, the employed hierarchy of effects model introduced by (Lavidge and Steiner, 1961) contains six stages from awareness of the product to final purchase of product as follows:

- Awareness

- Knowledge

- $\quad$ Liking

- $\quad$ Preference

- Conviction

- Purchase

\section{Method: Event Study}

In this section, we present a case study where big social data of Jolla Oy and Nokia Oyj is collected from their respective Facebook pages. We employed social set analysis (SSA) 
Menon et al.

as a novel method to (a) understand temporal dynamics of interaction, (b) detect crowdfunding campaign post hoc and, (c) conduct an event study of users' sociotechnical interactions, brand associations, emotions, as well as, consumer decisions before, during and after the detected crowdfunding campaign events. Event studies is a finance methodology to assess an impact on corporate wealth (e.g. Stock prices) due to events such as restructuring of companies, leadership change, mergers \& acquisitions (Bromiley et al., 1988; MacKinlay, 1997; McWilliams and Siegel, 1997). While there is no unique structure for event study methodology, at a higher level of abstraction, it contains identifying three important time periods or windows. First, defining an event of interest (in our case, crowdfunding campaign) and identifying the period over which it is active (event window), second, identifying the estimation period for the event (pre-event or estimation window), and third, identifying the post-event window (MacKinlay, 1997).

The following are the reasons to select these two companies for the event study: similar products and markets, same country of origin (Finland) and catering global markets. same launch date and venue (Slush 2014, Helsinki, Finland), different sales strategy - Jolla Oy, started crowdfunding campaign for selling and developing the Jolla Tablet, whereas, Nokia Oyj, used the traditional approach of launching a product and selling it to the target market.

We investigated the interactions of the fanbase for both the companies before, during and after crowdfunding campaign. We discuss the results, present substantive interpretations of the findings, implications of crowdfunding on fanbase development, and conclude with future work.

\subsection{Case Description}

Nokia $\mathrm{Oyj}^{1}$ currently focuses on large-scale telecommunications infrastructures, technology development and licensing, and online mapping services. Nokia has approximately 57, 000 employees around the world, headquarters in Espoo, Finland. In 2014, Nokia employed 61,656 people across 120 countries, conducted sales in more than 150 countries and reported annual revenues of around $€ 12.73$ billion. Nokia N1 is an Android tablet developed by Nokia. Unveiled on 18 November 2014, it is Nokia's first mobile device since the sale of its original mobile phone business to Microsoft earlier that year.

Jolla Ltd., ${ }^{2}$ established in 2011, is a mobile company from Finland that is developing mobile devices and Sailfish OS, the independent mobile operating system. In November 2014 Jolla introduced the Jolla Tablet project, aiming to hit the markets in Q2/2015. Jolla has 125 employees working in (Helsinki and Tampere) Finland and Hong Kong.

\subsection{Sales Strategy: Nokia N1 v. Jolla Tablet}

The launch of Nokia's tablet product was done in the traditional way, which means that they launched the concept and announced the release date for sales in China (January 2015) of Nokia N1 in Slush 2014. So, in essence, for Nokia, Slush was a Product Concept Launch and release date announcement platform.

${ }^{1}$ http://company.nokia.com/en/about-us/ourcompany

${ }^{2}$ https://jolla.com/about/ 
Analysing the Role of Crowdfunding in Entrepreneurial Ecosystems: A Social Media Event Study of Two Competing Product Launches

\subsection{Data Collection: SODATO}

Table 3. Facebook data corpus

\begin{tabular}{|l|l|l|}
\hline Attribute & Nokia & Jolla \\
\hline From & $2008-12-31$ & $2011-10-01$ \\
\hline To & $2015-05-06$ & $2015-05-04$ \\
\hline Total Posts & 2,808 & 1,439 \\
\hline Total Comments & 847,323 & 7,247 \\
\hline Total Likes & $14,473,345$ & 103,369 \\
\hline Total Unique Actors & $3,048,263$ & 40,242 \\
\hline
\end{tabular}

Facebook data was collected using the Social Data Analytics Tool (SODATO) (Hussain et al., 2014; Hussain and Vatrapu, 2014a, 2014b). SODATO enables the systematic collection, storage, and retrieval of the entire corpus of social data for a public Facebook wall, in our case for the official Facebook walls of Nokia ${ }^{1}$ and Jolla ${ }^{2}$. Table 2 above provides a description of the Facebook data corpus.

3.3.1. Data Processing. We used data warehousing and on-line analytical processing technology using Microsoft SQL Server database to conduct temporal analysis. We designed a multidimensional data model for Facebook data using interactions as numeric/fact measures. The interactions measure data is further processed across several dimensions: temporal (daily, weekly, monthly, and yearly), actions (post, comment, and like), actors (admin and non-admin) and artifacts (posts and comments). Since the type of interactions that can be performed by various actors on a post artifact include comment and like, using a multidimensional approach is required.

3.3.2 Data Analysis. We empirically analyze the fanbase behavior for both the companies before, during and after Slush 2014. The aim of the case study is to analyze the impact of Jolla's crowdfunding campaign on Jolla's fanbase. This impact of crowdfunding will be compared with Nokia's traditional approach of launching a product and selling it on the market. We discuss the results, present substantive interpretations of the findings, implications of crowdfunding on fanbase development and conclude with directions for future work.

Slush 2014 is the focal point for startups and technical talent to meet with top-tier international investors, executives and media in Finland. In 2014, Slush brought together over 14,000 attendees and probable fans and more than 3,500 companies for the two-day event.

\footnotetext{
1 https://www.facebook.com/nokia

2 https://www.facebook.com/jollaofficial
} 
Menon et al.

\subsection{Social Set Analysis}

For big social data analytics of Facebook or Twitter data, the fundamental assumption of Social Network Analysis (SNA) that social reality is constituted by dyadic relations and that interactions are determined by structural positions of individuals in social networks (Mizruchi, 1994) is neither necessary nor sufficient (Vatrapu et al., 2014). To overcome this limitation and address it, (Mukkamala et al., 2014; Müllerleile and Joenssen, 2015; Vatrapu et al., 2014; Zheng et al., 2014), have proposed an alternative holistic approach to big social data analytics called Social Set Analysis (SSA).

SSA is based on the sociology of associations and the mathematics of set theory and supports both interaction analytics in terms of actors involved, actions taken, artifacts engaged with as well as text analytics in terms of keywords employed, feelings expressed, pronouns used and topics discussed (Mukkamala et al., 2014; Müllerleile and Joenssen, 2015; Vatrapu et al., 2014; Zheng et al., 2014). For the purposes of this article, we employ SSA to uncover the temporal distribution of user interaction and engagement on the Facebook walls as well as with respect to the wall admin (the case company's Facebook wall account), and unique actor sets before, during and after events of theoretical interest (in our case, the crowdfunding campaign), and overall actor mobility between the two Facebook walls.

\subsection{Social Text Analysis}

In this section, we describe the text analytics methodology that was applied to analyze Facebook posts and comments of both Jolla and Nokia. The text corpus primarily contains 1183 and 24978 posts/comments of Jolla and Nokia Facebook walls respectively, for the time period from 2014-10-27 to 2014-12-31. In order to analyze the text corpus, we have used both text mining and machine learning techniques as shown in Figure and also as explained later.

\subsubsection{Language Detection and Text Extraction}

The Facebook walls of both Nokia and Jolla contain comments/posts in different languages primarily English, Finnish and so on. Since majority of post/comments belong to English language, as also mentioned before, our analysis in this research work is limited to English posts and comments. We used a custom script written in Python Language using Natural Language Toolkit (NLTK) (Bird, 2006) to identify and separate the English language posts and comments from the Facebook data. One of the challenges in language detection of Facebook texts is that, some of the posts/comment texts are written in multiple languages mixed together. After identifying and separating the English texts, in order to ensure the accuracy of language detection, we manually went through around 800 posts/comments randomly and found only 6 false positives and therefore the accuracy of language detection was quite high around $99.3 \%$.

\subsubsection{Text Preprocessing}

After collecting English language posts/comments of Nokia and Jolla, then we preprocessed the texts into tokens, by breaking them into sentences and words by using space as delimiting character between the words using NLTK and Python. As part of PreProcessing step, we further processed the raw text tokens by removing non-alphabetical and numerical characters, stop words that are high-frequency words (like the, to, also, so on) which don't contribute much to the semantic meaning of the documents. The final 
Analysing the Role of Crowdfunding in Entrepreneurial Ecosystems: A Social Media Event Study of Two Competing Product Launches

output of this step ended up in raw text containing approximately 7, 499 and 123, 412 tokens for Jolla and Nokia respectively, which are used as an input for further processing using text mining techniques.

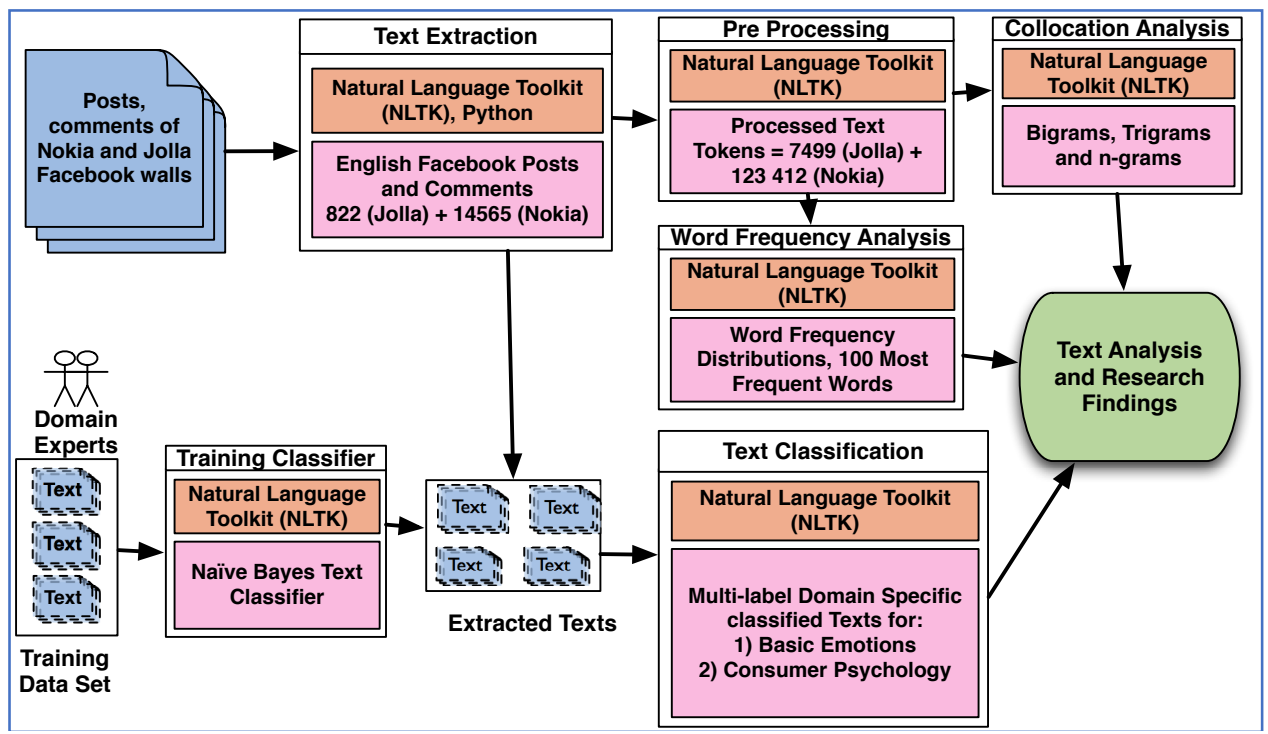

Figure 2 Text Analytics Methodology of Facebook Posts and Comments

\subsubsection{Word Frequency Analysis}

Word frequency analysis is a method of automatically identifying the frequent occurring words from a given text corpus, by using the term document matrix. In order to compute the word frequencies, raw tokens from the pre-processing step are further analyzed using NLTK to prepare term document matrix containing the frequency of words across the text corpus of Facebook posts and comments. We have computed the term document matrix for text corpus of a Facebook wall by combining all the posts and comments of that individual wall (e.g. Jolla). The construction of term document matrices enables us to find most frequent words (e.g. 100 most frequent words) with the word frequencies, which are used to generate word cloud for a given document. Word clouds or tag clouds is a simple way of visualizing or highlighting the most frequently used words from a given text document. As part of the analysis, we have generated word clouds for each Facebook wall and also considering the event time periods: before, during and after. Word frequency analysis and word clouds provide a quick overview of major concepts / topics discussed in the text corpus.

\subsubsection{Collocation Analysis}

Collocations are expressions of multiple words, which commonly co-occur in the text documents and it is a sequence of words that occur together unusually often in the text documents. Finding collocation expressions involve standard statistics-based and linguistically rooted association measures against mere frequency of word occurrence counts. The collocation analysis provides insights about the documents by providing bigrams, trigram and n-grams that contain words, which co-occur in the documents. The 
Menon et al.

collocation analysis for each Facebook wall was conducted using NLTK to find out bigrams and trigrams. The collocation analysis provides an intuition about the topics and concepts that are being discussed in posts/comments of Facebook.

\subsubsection{Machine Learning and Text Classification}

As part of the methodology, we applied machine learning algorithms on the text corpus to perform domain specific text classification tasks. Text classification approach comes under supervised machine learning and it can be defined as a process where assigning a predefined category of labels to new documents based on probabilistic measure of likely hood using a training set of labelled documents (Yang and Liu, 1999). When compared to dictionary-based approaches for classification, supervised approaches have an advantage that they allow researchers to use their own domain specific models (e.g. (Ekman, 1992)six basic emotions, Consumer Psychology) for classification as the domain experts/researchers themselves can code the training sets, whereas the dictionary based approaches are primarily limited to the models for which dictionaries are already available.

Out of several machine learning algorithms (e.g. Logistic Regression, Neural Networks) available for text classification, we have chosen a simple text classification method, Naïve Bayes classifier (Zhang and Li, 2007) based on Bayes rule that relies on a simple representation of text documents using bag of words approach. The Naïve part of the classifier is that it assumes that the conditional probability of a word, given a category is independent from the conditional probabilities of other words given that category. However, the Naïve Bayes assumption makes the classifier far more efficient and practical than the exponential complexity of other classifiers and also it works quite well for the text classification with a fair amount of accuracy and therefore it stands as one of the most used techniques for text classification (Yang and Liu, 1999; Zhang and Li, 2007). Therefore, in this research work, we used Naïve Bayes classifier to classify the extracted English posts and comments from the Facebook walls of Nokia and Jolla for the domain specific models: 1) Basic Emotions (Ekman, 1992) and 2) Consumer Psychology and Hierarchy Of Effects (Lavidge and Steiner, 1961).

With regards to emotions there are many list/models (Ortony and Turner, 1990) about what constitutes the concept of basic emotions, but in our research work, we used a model containing six basic emotions proposed by (Ekman et al., 1983) as shown below.

- Basic Emotions

$\begin{array}{ll}\circ & \text { Anger } \\ \circ & \text { Disgust } \\ \circ & \text { Fear } \\ \circ & \text { Joy } \\ \circ & \text { Sadness } \\ \circ & \text { Surprise }\end{array}$

In order to classify the posts/comments of the Jolla and Nokia walls, we have a used training sets containing around 10000 Facebook post/comments from similar domain that are manually coded for both Basic Emotions and Hierarchy of Effects domain specific models. After training the classifier sufficiently with the given training sets, it was used to classify the extracted Facebook post/comments of Nokia and Jolla walls individually. 
Analysing the Role of Crowdfunding in Entrepreneurial Ecosystems: A Social Media Event Study of Two Competing Product Launches

\section{Findings}

\subsection{Distribution of Artifact Associations}

Jolla launched the product concept and the crowdfunding campaign on the same day and at the same time in Slush 2014. This allowed the fans to see the product and invest in it (pre-purchase) at the same time.

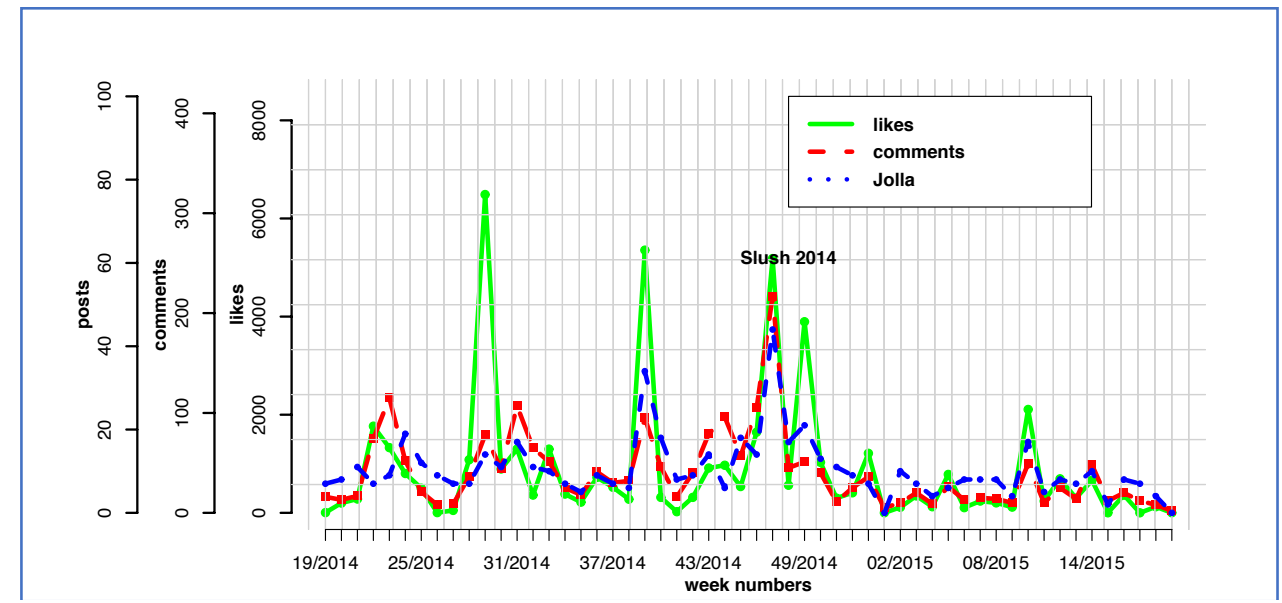

Figure 3. Temporal Distribution of Jolla's Facebook Data posts (Posts, Comments and Likes)

Figure 3 shows that in Jolla's case, there is constant interaction in terms of likes and comments to the posts of Jolla on Facebook. The interaction with Jolla, in terms of comments reaches highest level during Slush 2014.

We also observed that unlike Nokia, users not only like and comment on admin's posts but they can also submit posts on Jolla's Facebook wall. Thus, Jolla's Facebook wall interaction consists of posts, comments and likes by both the admin (Jolla) as well as the Facebook users. To account for this crucial difference in user interaction modes between our two case companies, we conducted an additional temporal analysis of the Facebook users' interaction on posts and comments made by Jolla by filtering out the non-admin posts. Figure 4 shows the temporal distribution of posts and comments by Jolla and user interaction with them in terms of likes and comments. 


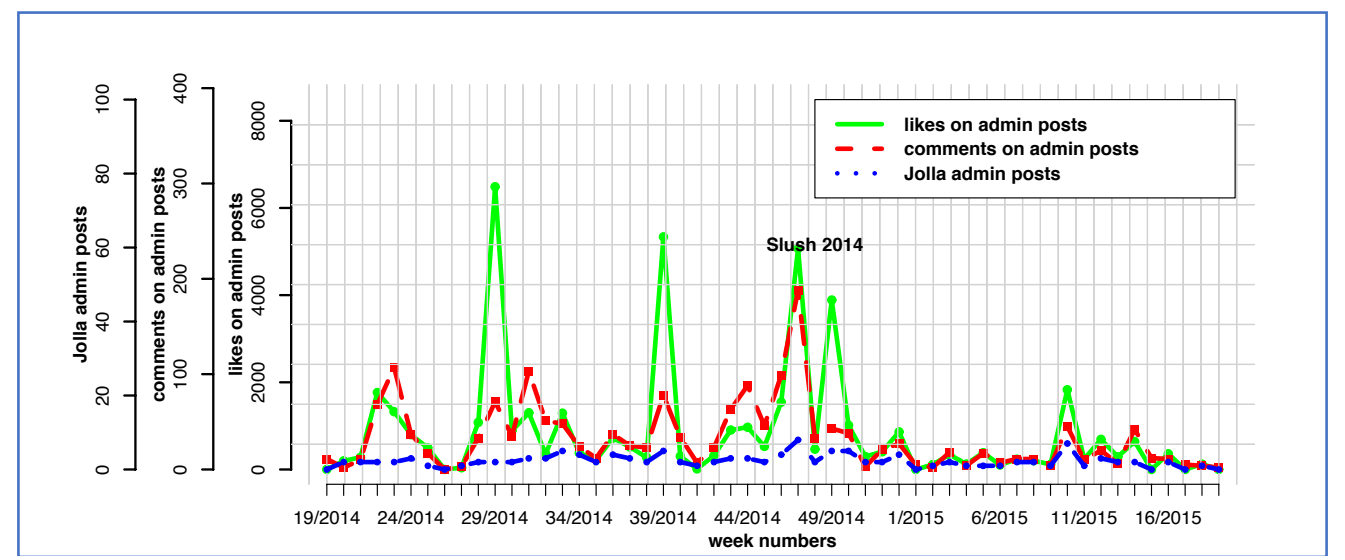

Figure 4. Temporal Distribution of Jolla's Admin Facebook Data (Posts, Comments and Likes)

Comparing Figure 3 (admin + non-admin interaction) with Figure 4 (non-admin or users) interaction on admin (=Jolla) posts and comments, we find that most of the user interaction was directed towards Jolla admin artifacts i.e. posts and comments made by the admin.

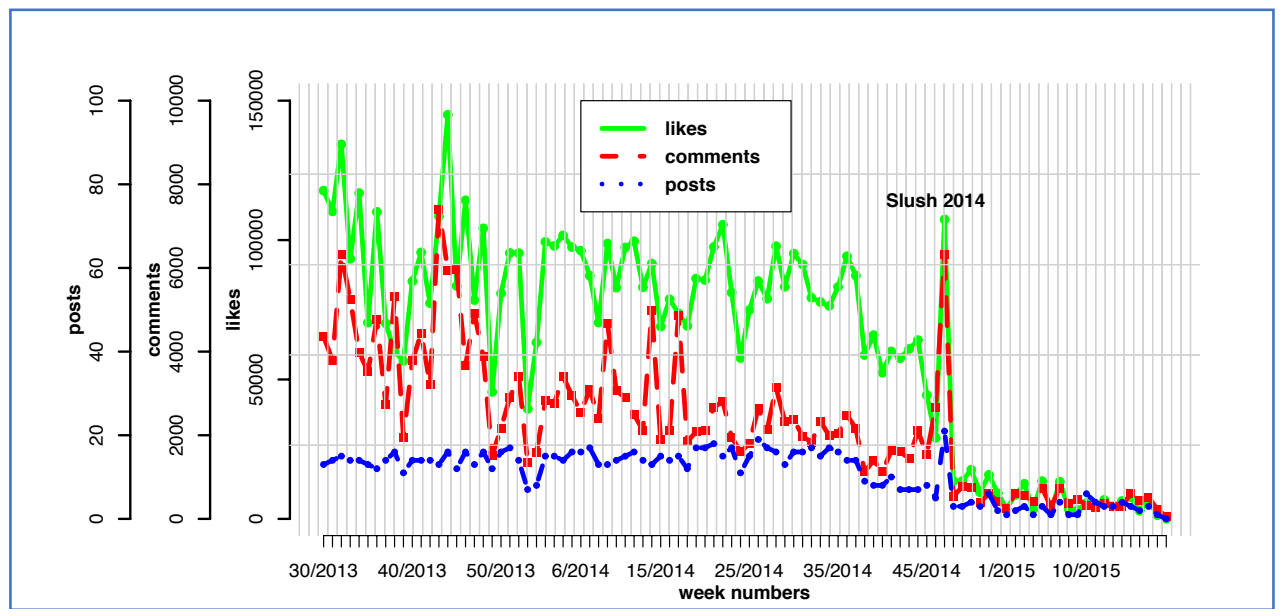

Figure 5. Temporal Distribution of Nokia's Admin Facebook Data (Posts, Comments and Likes)

Figure 5 shows that the number of likes to the posts by Nokia before Slush 2014 is significantly high. The number of likes drops significantly after Slush 2014. There is also a good user interaction towards Nokia in terms of comments to posts by Nokia before Slush 2014. This interaction to Nokia based on comments keeps declining but not as significantly as in case of likes after Slush 2014.

\subsection{Distribution of Actor Associations}


Analysing the Role of Crowdfunding in Entrepreneurial Ecosystems: A Social Media Event Study of Two Competing Product Launches

Having analyzed the temporal distribution of user interaction as shown in Figures 4-6, we analyzed the patterns of actors by constituting sets across space (Facebook walls of Nokia and Jolla) and time (3-weeks before, during and after the Slush crowdfunding campaign).

4.2.1. Actors Sets across Space. Figure 6 presents the finding that there are only 16 actors (Facebook users) in common between the Nokia and Jolla Facebook walls. This is quite a surprising finding given the origins of Jolla from Nokia in terms of personnel and technology.

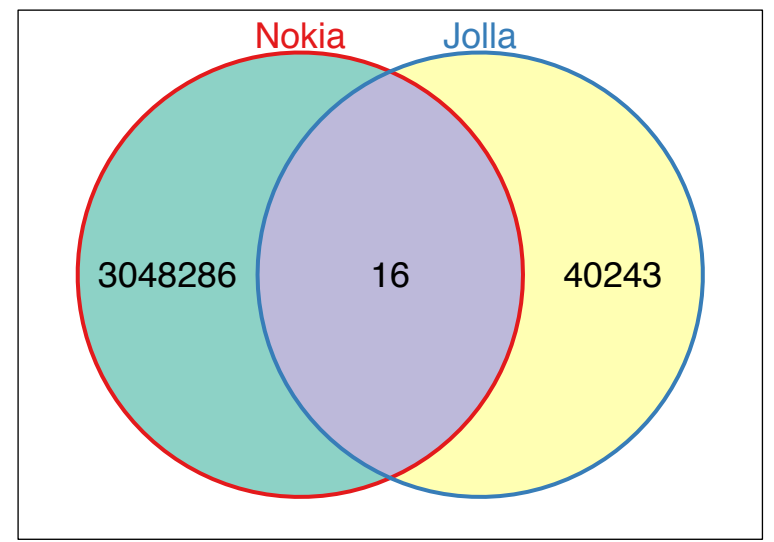

Figure 6. Social set analysis of Nokia and Jolla Facebook Actors

4.2.2. Actors Sets across Time. We then investigated Facebook actor sets with respect to the Slush crowdfunding campaign across 3 -weeks periods before, during and after the Slush crowdfunding campaign. Figure 7 describes the number of unique and common fans on Facebook, 
Menon et al.

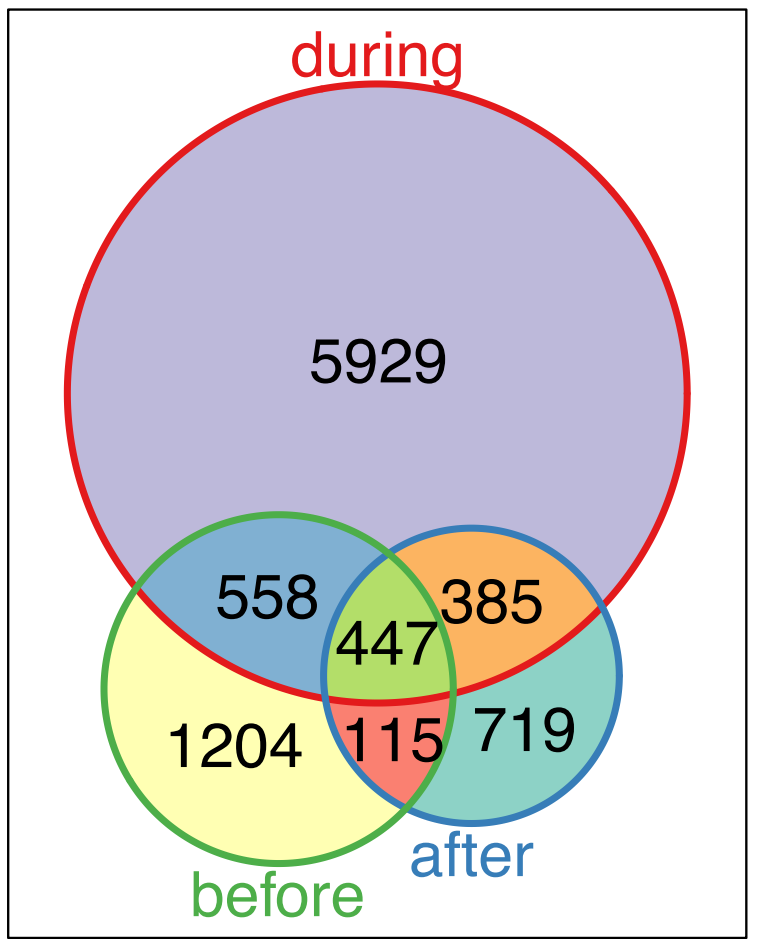

Figure 7. Social set analysis of Jolla Facebook data

For Jolla (Figure 7), there is a significantly larger (5929 unique actors) user interaction during the campaign period when compared to before (1204 unique actors) and after (719 unique actors) the campaign period. There are 447 unique actors involved in all the three stages (before, during and after). 


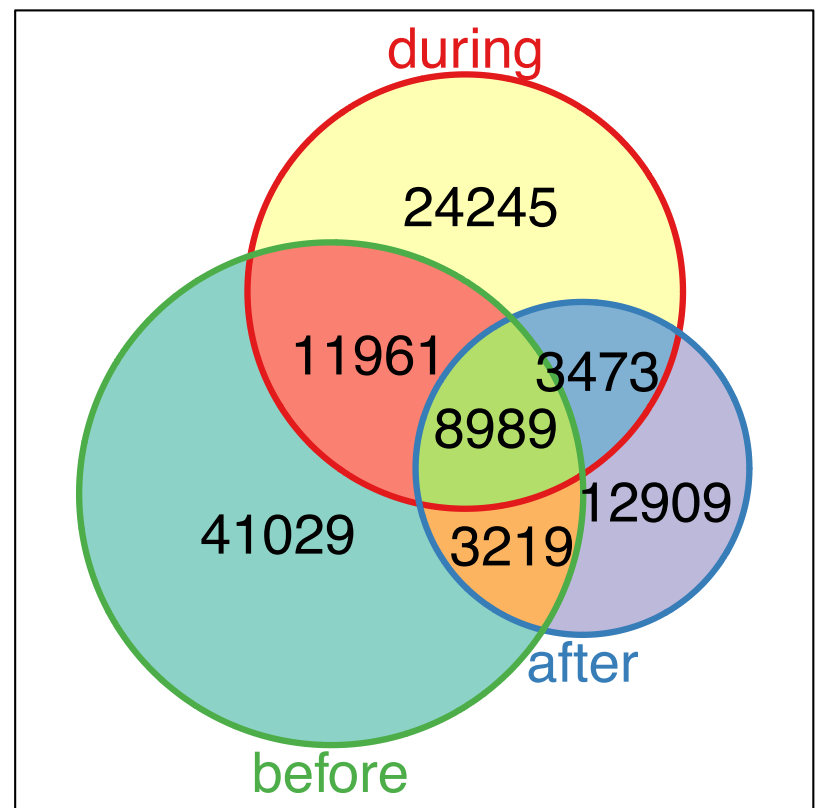

Figure 8. Social set analysis of Nokia Facebook data

In case of Nokia (Figure 8), there is a significantly large (41029 unique actors) user interaction before the campaign when compared to during (24245 unique actors) and after (12909 unique actors) the campaign. There are 8989 unique actors involved in all the three stages (before, during and after) of the campaign.

Table 4. Social Set Analysis

\begin{tabular}{l|l|l|l}
\hline & Total No. of days & \multicolumn{1}{|c|}{ Jolla } & Nokia Oyj \\
\hline Before Campaign & 22 & 2324 & 65198 \\
\hline During Campaign & 21 & 7319 & 48668 \\
\hline After Campaign & 23 & 1666 & 28590 \\
\hline During Campaign + After Campaign & 44 & 8985 & 77258 \\
\hline $\begin{array}{l}\text { Fans/day } \\
\text { (Before Campaign) }\end{array}$ & 22 & 105 & 2963 \\
\hline $\begin{array}{l}\text { Fans/day } \\
\text { (During + After Campaign) }\end{array}$ & 44 & 204 & 1756 \\
\hline
\end{tabular}




\section{Menon et al.}

To facilitate comparison of the two cases, we created the following formula to assess the impact of the different sales approaches on the user interaction:

$I \%=\frac{T-B}{B}$

I- Increase in the Interaction of Fans/day

$T$ - Total of Fans/Day (During Campaign + After Campaign)

$B$ - Total of Fans/Day (Before Campaign)

Using the formula and Table 4 we were able calculate the increase in the user interaction for Jolla (194\%) and the decline in the user interaction for Nokia (40.7\%) from before to after the campaign period.

\subsection{Distribution of Word Associations}

As part of social text analysis of the data corpus, we conducted word cloud analysis of the 50 most frequent words in the content of posts and comments on Nokia and Jolla for 3-week periods before, during and after the Slush crowdfunding campaign. (We excluded the most frequent words "Nokia" and "Jolla" from their respective word clouds).

A word cloud is a visual illustration to provide a visual view of an instance or a group of instances that have something in common (e.g., search results for a specific instance). In the word cloud, the terms are listed in an alphabetical order and the font size or color determines the importance of the word (Carmel et al., 2012).

Table 5 presents the word clouds for Jolla and Nokia in the 3-week period before, during and after the Slush and Jolla's crowdfunding campaign.

Table 5. Word Cloud of most frequent words

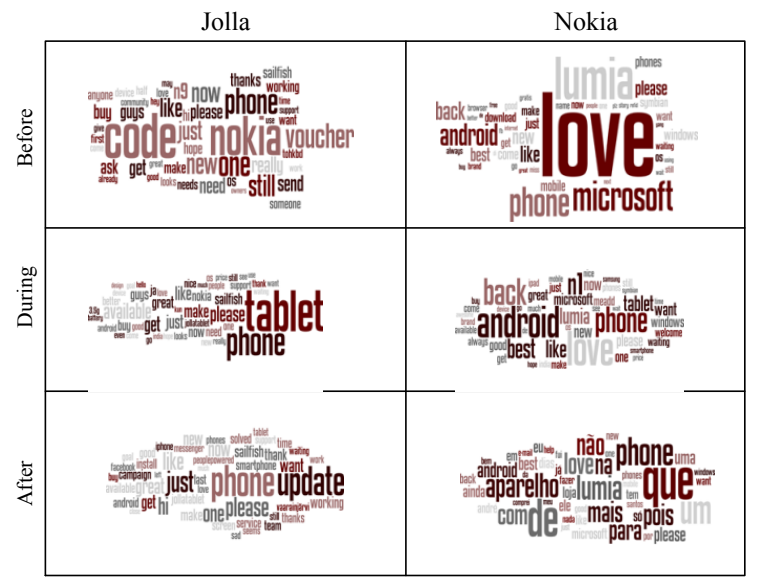

Based on Table 5, it can be observed that in Jolla's Facebook discussions during the "Before" period, some of the most common words that appear are, Nokia, N9, Phone, Buy, Code, Need. Jolla is a spin-off company from Nokia based on Nokia's N9 phone, hence features amongst frequent words on Jolla's Facebook page before the crowdfunding campaign period. In Jolla's "During" period, the word cloud shows words like, Tablet, Phone, Buy, Need that indicate fans' interest towards buying the tablet 
Analysing the Role of Crowdfunding in Entrepreneurial Ecosystems: A Social Media Event Study of Two Competing Product Launches

product and/or the phone product. Finally, the "After" period of Jolla indicates an enquiry from the fans towards the crowdfunded product. This is evident from words like, Please, Update, Want, Waiting, Get.

The word clouds for Nokia in the 3-week period before, during and after the Slush crowdfunding campaign are also presented in Table 5. It can be observed from "Before" period of Nokia that the words, Love, Lumia, Microsoft, Android, Phone indicate a transition from Nokia mobile phones to Microsoft for the fans and Android as an operating system for the phones. The product release for Nokia N1 tablet can be observed from "During" period of Nokia. The words N1, Tablet, Android, Love indicate towards the new Nokia N1 tablet and Android operating system. Whereas, "After" period for Nokia does not have the words; Tablet, N1 in the most frequent words giving an indication of reduction in interest towards the tablet product. A possible reason for this drop could be that - unlike Jolla did through the crowdfunding campaign - Nokia did not give any channel to the consumers to buy the product.

\subsection{Distribution of Text Emotions}

In order to better understand the product and brand perceptions of Nokia and Jolla we conducted emotion analysis of the Facebook posts and comments. Figure 9 illustrates the identified emotions of the Jolla Facebook posts and comments in English and Figure 10 of the emotions of Nokia consequently.

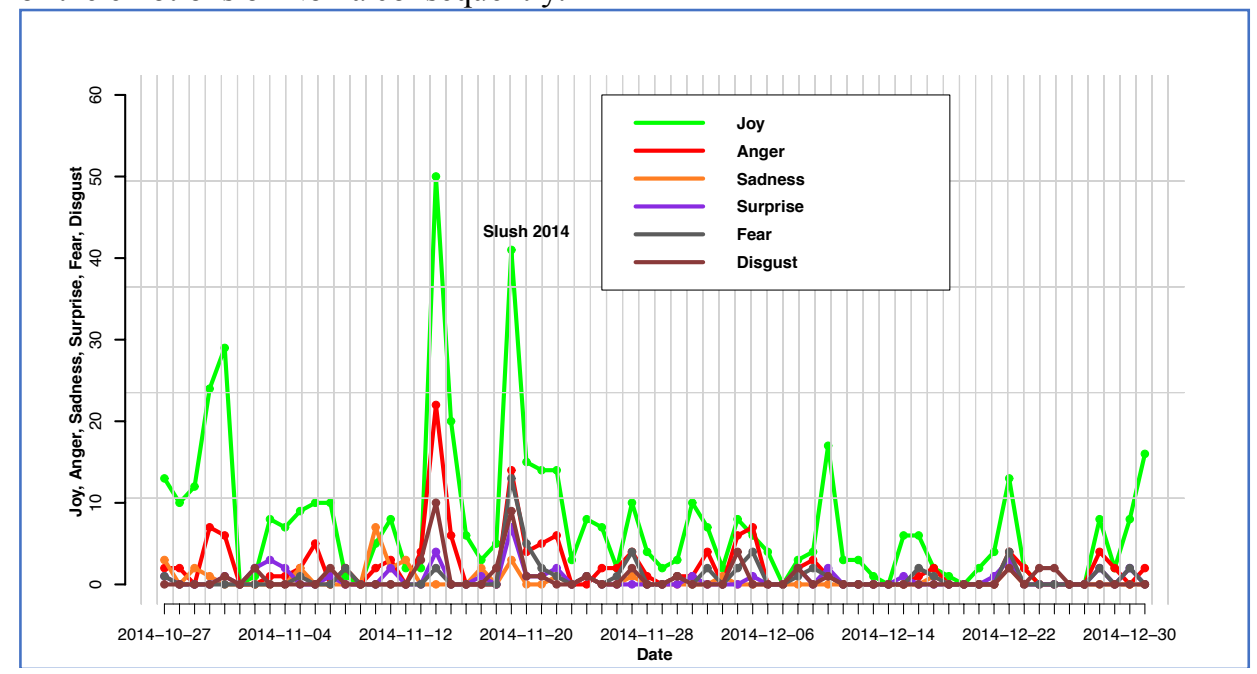

Figure 9. Emotion analysis of Jolla Facebook text.

Emotion analysis of Jolla reveals that joy is the dominant emotion in the Facebook posts and comments, with significant peaks pre-product launch (2014-11-14) and at the time of product launch at Slush (2014-11-19). Several smaller peaks of joy are also observed during the crowdfunding campaign. Together with the amount of interactions (Figure 4) the emotions indicate the success of sales promotion efforts of the company. 


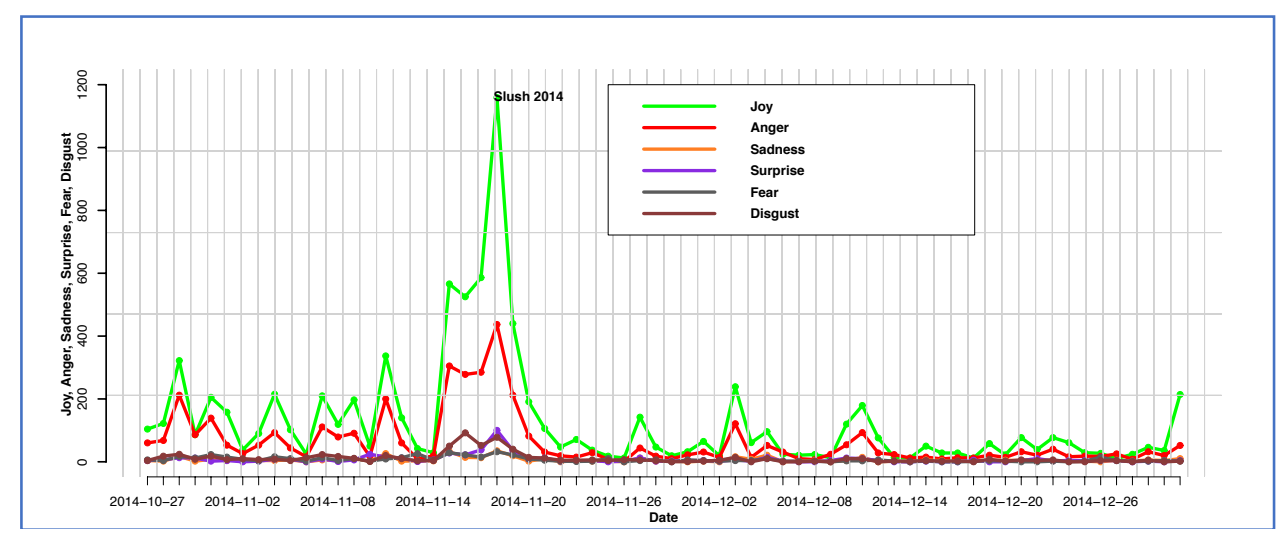

Figure 10. Emotion analysis of Nokia Facebook text.

Emotion analysis of Nokia Facebook reveals similarly that joy is the dominant emotion in the Facebook posts and comments. Interestingly, the peak in joy is at the time of product launch at Slush (2014-11-18), whereas after the product launch the amount of joy is proportionally smaller than before the product launch.

\subsection{Distribution of Stages of Consumer Behavior}

In order to better understand the consumer behavior of Nokia and Jolla we conducted stages of consumer decision making analysis of the Facebook posts and comments. Figure 11 illustrates the identified stages of consumer decisions of the Jolla Facebook posts and comments written in English and Figure 12 of the consumer decisions of Nokia consequently.

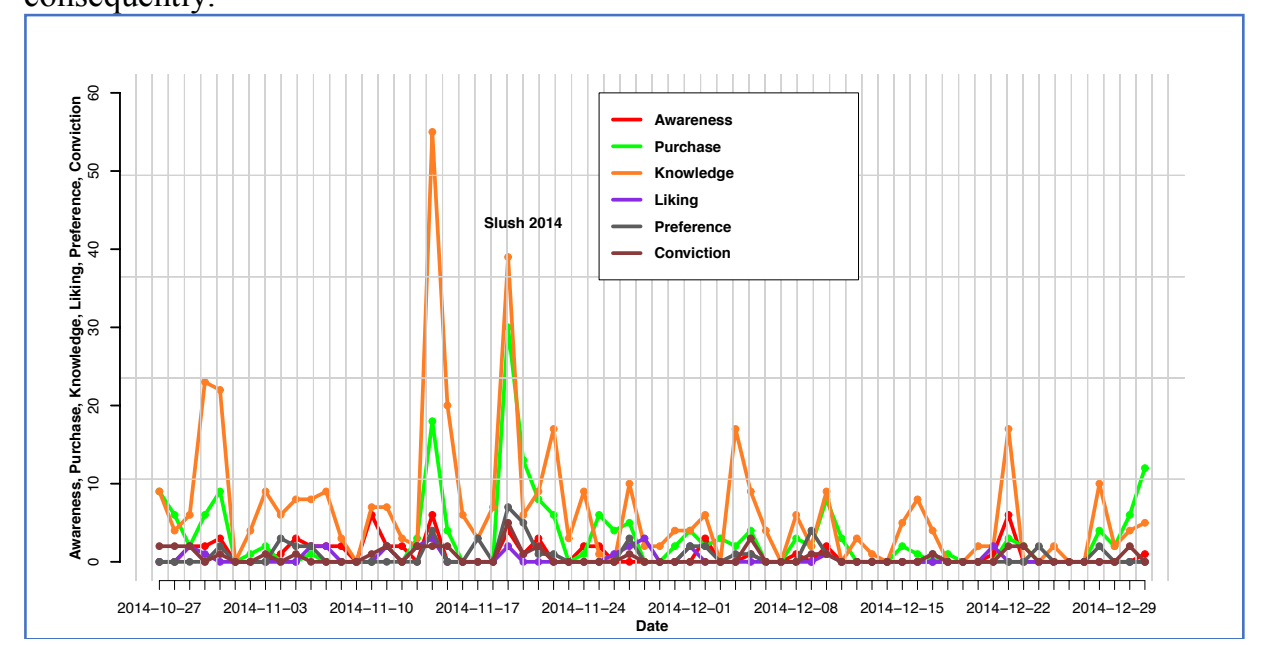

Figure 11. Consumer Decision Making analysis of Jolla Facebook text.

In case of Jolla, the Hierarchy of Effects (Lavidge and Steiner 1961) started to show in the Facebook conversations on the day of the product launch during Slush. Jolla had enabled product sale over Indiegogo's Crowdfunding platform, which enabled the people to make purchase decision effectively and immediately. This phenomenon of running through the Hierarchy of Effects (Lavidge and Steiner 1961) to arrive to Purchase 
Analysing the Role of Crowdfunding in Entrepreneurial Ecosystems: A Social Media Event Study of Two Competing Product Launches

decision making is observed in Figure 12 for Jolla. It can be observed that consumer got the knowledge (indicated by yellow in Figure 11) of the new tablet product on $19^{\text {th }}$ November 2014 (Slush), when Jolla launched the crowdfunding campaign. This allowed the customers to make the purchase the very same day (indicated by green in Figure 11). Majority of the posts and comments during the day were classified as Knowledge or Purchase related, following that also Preference, Conviction and Liking were visible to a lesser degree.

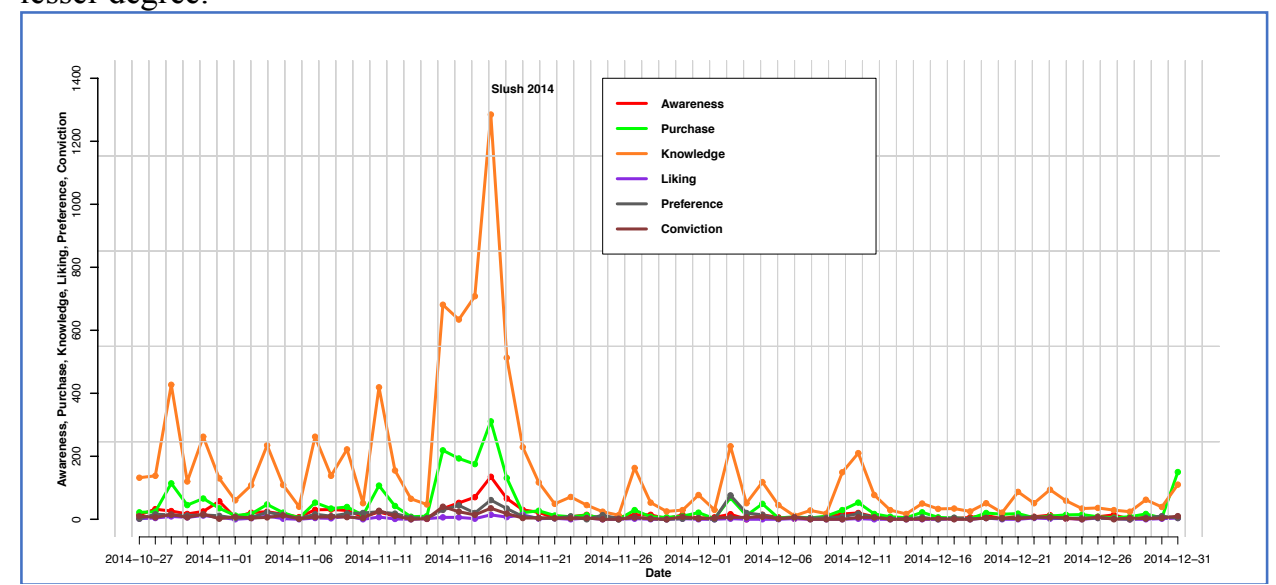

Figure 12. Consumer Decision Making analysis of Nokia Facebook text.

In case of Nokia, it is also observed that the Hierarchy of Effects (Lavidge and Steiner 1961), started to appear on the day of the product launch $\left(19^{\text {th }}\right.$ November 2014 , Slush). There was one difference between Jolla and Nokia's sales strategy, Jolla went for crowdfunding and Nokia on the other hand decided to go through retail channels but the sales for Nokia would start only in January 2015. Hence, it can be seen that there is knowledge (indicated by orange in Figure 12) about the Tablet product for Nokia's fans but they did not have a way to buy it immediately. This can be observed from the Figure 13 , as the intensity of green (representing Purchase) is very less when compared to the intensity of orange (representing Knowledge). Furthermore, unlike in the case Jolla, the intensity of Purchase intentions identified from the text remain low after the product launch and do not similarly follow the trends of Knowledge.

\section{Discussion and Conclusions}

In this paper, we have applied Social Set Analysis (SSA), text analysis and emotion analysis for investigating social media activity related to two competing product launches. SSA allows insights on the overall volume of a company's fanbase activity. It also shows the ways in which members of the fanbase move in between the key phases of company evolution. Here, we have used SSA to investigate how the fanbases of two competitive ecosystems, Nokia and Jolla, have interacted with the companies before, during, and after a product launch. Moreover, using SSA, we analyzed the possible 
Menon et al.

overlaps between their respective fanbases and showed that they share a very small number of fans.

SSA results presented earlier showed the voluminous but also transient nature of interactions during crowdfunding campaigns and a diversity of aggregate user behavioral patterns. Overall, our findings are similar to prior results from SSA event studies of corporate social media crises (Raghava Rao Mukkamala et al., 2015; R.R. Mukkamala et al., 2015). It is interesting to note that social media crises and crowdsourcing campaigns share not only structural similarities from an event study methodologies perspective (before, during and after), but they also yield similar interactional patterns in terms of temporal dynamics and positive and negative brand associations.

We are aware of the fact that branding strategies and tactics differ significantly between an established brand such as Nokia and a new brand such as Jolla. Further, we are also not interested in isolating the effect of crowdfunding campaigns from a "treated" Jolla vs. "untreated" Nokia ecosystems comparison. Our application of SSA event study to the crowdfunding campaign was not concerned with the "supply-side" marketing strategies and tactics of Nokia and/or Jolla in that context. Instead, our analytical objective was to employ SSA to uncover and better understand the "demand-side" dynamics of users' brand associations in terms of "Facebook likes" on brand posts and keyword analysis of their comments aggregated as word clouds.

We further investigated the impact of crowdfunding in terms of emotions and stages of consumer behavior of the fans in the two competing product launches. We think that SSA combined with netnography and content analysis in terms of sentiment analysis and topic discovery can reveal the different strategies employed by the organizations to manage the crowdfunding campaigns. That is part of our proposed future work. Based on findings from SODATO analyses, we propose the following:

Proposition 1. Crowdfunding increases engagement in terms of fanbase interaction.

SSA of Jolla shows a significant increase in user interaction (posts, comments and likes) of Facebook fans during and after the crowdfunding period when compared to before the crowdfunding period (Table 3). The rate of increase in fanbase interaction (see formula in section 4.2.2) related to the tablet product on a daily basis was $194 \%$ for Jolla from before to after the crowdfunding period. In case of Nokia, there was a decline in the user interaction. This decline was $40.7 \%$ for Nokia on the daily basis.

Proposition 2. Crowdfunding increases emotional engagement to the brand community. Text analysis of Jolla shows that there is continuous emotional engagement in terms of joy (orange line in Figure 9) after the product launch and during the crowdfunding campaign. Whereas text analysis of Nokia shows discontinuous and less intense joy emotion (orange line in Figure 10) after the product launch.

\section{Proposition 3. Crowdfunding enhances engagement in terms of purchase intention}

By conducting text analysis, using Hierarchy of Effects approach (Lavidge and Steiner, 1961), we propose that crowdfunding enhances the movement towards purchase in comparison to traditional sales approach. For Jolla right after the product launch the crowdfunding campaign was launched which allowed the customers to pre-purchase the product immediately. The purchase intention (green in Figure 11) and knowledge about 
Analysing the Role of Crowdfunding in Entrepreneurial Ecosystems: A Social Media Event Study of Two Competing Product Launches

the product (orange in Figure 11) are in coherence for the timeline of investigation as shown in Figure 11. In case of Nokia, after the product launch the customers did not have an immediate purchase channel (like crowdfunding for Jolla), hence, there is a big difference between purchase intention (green in Figure 12) and knowledge of the product (orange in Figure 12). For Nokia the purchase intention reduces further after the product launch as expected because there was no direct sales channel opened by Nokia till early January 2015. Based on the analysis of the product launches, a crowdfunding campaign can support all the phases of the Hierarchy of Effects, and enhance the engagement towards purchase intention during the campaign.

Proposition 4. Crowdfunding increases engagement in terms of sustainability of brand community associations.

Based on calculation of ratio (Table 3) after/before fanbase interaction Jolla's interaction (ratio of 0.72 after and before interaction in terms of comments, posts, and likes) is more sustainable compared to Nokia interaction (ratio of 0.44 after and before interaction). By looking at the trends Figure 4 of Jolla and Figure 5 of Nokia this impact to sustainability is easy to observe visually in a longer term

Proposition 5. Crowdfunding facilitates the evolution of entrepreneurial ecosystems by creating engagement within brand communities.

This more generic proposition binds together the previous four propositions, and extends the implications to entrepreneurial ecosystems' level. Crowdfunding also extends the market mechanism to products and services that are not yet part of companies' offering. This allows consumers to express and interest in new offerings and even prioritize their development. Moreover, crowdfunding introduces a mechanism for the focal company to invite developers or complementarities to introduce their offering and collect funding and conduct co-creation. Second, crowdfunding is a completely new way to fund the development of products and services. In other words, crowdfunding can be considered a new entrepreneurial ecosystem instrument supporting seed funding for new companies as well as a source of investment for companies developing new products and services. Finally, it is important to realize that crowdfunding itself is an application of platformbased business ecosystem giving leverage to through a multi-sided market of companies running campaigns for themselves and their complementors, addressing potential customers and consumers, some of which are also part of the business ecosystem of the crowdfunding platform.

The last proposition is a preliminary one in the sense that we will need some additional data (for example, crowdfunding platform data, company creation and venture capital investment data, and Facebook conversations between fans, ) to elaborate and validate it. In future it would be interesting to use the above additional data sources and analysis methods including Social Network Analysis to investigate the impact of crowdfunding.

Future work includes accessing and aggregating 1) data that represents the interconnections and interactions between individual social media actors and 2) data from the crowdfunding platforms representing the individual investments both for the focal campaign(s) under investigations as well as related campaigns. 
Menon et al.

We claim that this paper contributes to entrepreneurial and ecosystems research in an important manner. Making use of quantitative data-driven approach, not used in a similar manner and context previously to our best knowledge, we have shown that crowdfunding has clear potential in engaging potential and existing customers in various ways, in terms of actual interaction, emotional engagement, purchase intention, as well as in creating brand association sustainability. Crowdfunding campaign participants are among the lead users of new products and services, co-creating value with companies. As case Jolla shows, the focal company developing a ecosystem is able to start building traction for ecosystem complementors as well by allowing them to co-offer new products that create additional value to the ecosystem. Case Jolla is particularly interesting from this approach as it introduces a way for complementors to develop hardware products. The kinds of insights stemming bottom up from consumers complement the other novel views into business and innovation ecosystem interconnections, including Deals and Alliances, Executives and Finance, Angels and Startups (Basole et al., 2015; Rubens et al., 2011).

As for the limitations of this study, we currently only utilized data from one social media platform. We will explore also platforms such as Twitter, as well as crowdfunding platforms. These might provide support or refine the current propositions and help to further develop the propositions. Secondly, according to our definition of fanbase, we identify Facebook likers and commenters as company product fans in a rather straightforward manner. In further studies, we will elaborate in more detail how social media likers and commenters are related to actual loyal fans of companies by using other data sources and interviews.

\section{Acknowledgement}

This study was funded by the Academy of Finland (Cobweb project 295893)

\section{References}

Adelaar, T., Chang, S., Lancendorfer, K.M., Lee, B., Morimoto, M., 2003. Effects of media formats on emotions and impulse buying intent. J. Inf. Technol. 18, 247266. doi:10.1080/0268396032000150799

Adner, R., Kapoor, R., 2010. Value creation in innovation ecosystems: how the structure of technological interdependence affects firm performance in new technology generations. Strateg. Manag. J. 31, 306-333. doi:10.1002/smj.821

An, J., Quercia, D., Crowcroft, J., 2014. Recommending investors for crowdfunding projects. ACM, pp. 261-270.

Autio, E., 2015. Entrepreneurial and business ecosystems: What's different? | Global Entrepreneurship Development Institute [WWW Document]. URL https://thegedi.org/entrepreneurial-and-business-ecosystems-whats-different/ (accessed 12.30.16).

Autio, E., Thomas, L., 2014. Innovation ecosystems. The Oxford Handbook of Innovation Management. Oxford University Press, Oxford. 204-288.

Basole, R.C., Russell, M.G., Huhtamäki, J., Rubens, N., Still, K., Park, H., 2015. Understanding Business Ecosystem Dynamics: A Data-Driven Approach. ACM Trans. Manag. Inf. Syst. TMIS 6, 6.

Beier, M., Wagner, K., 2017. What determines the growth expectations of early-stage entrepreneurs? Evidence from crowdfunding. Int. J. Entrep. Small Bus. 31, 12. doi:10.1504/IJESB.2017.083839

Belleflamme, P., Lambert, T., Schwienbacher, A., 2014. Crowdfunding: Tapping the right crowd. J. Bus. Ventur. 29, 585-609. 
Analysing the Role of Crowdfunding in Entrepreneurial Ecosystems: A Social Media Event Study of Two Competing Product Launches

Berndt, A., Mbassana, M., 2016. Crowdfunding: The Beliefs of Rwandan Entrepreneurs. Bird, S., 2006. NLTK, in: Proceedings of the COLING/ACL on Interactive Presentation Sessions. Association for Computational Linguistics, Morristown, NJ, USA, pp. 69-72. doi:10.3115/1225403.1225421

Bitterl, S., Schreier, M., 2016. When Consumers Become Project Backers: The Psychological Consequences of Participation in Crowdfunding. SSRN Electron. J. doi:10.2139/ssrn.2827624

Bretschneider, U., Knaub, K., Wieck, E., 2014. Motivations for Crowdfunding: What Drives the Crowd to Invest in Start-Ups?

Bromiley, P., Govekar, M., Marcus, A., 1988. On Using Event Study Methodology in Strategic Management Research. Technovation 8(1-3), 25-42. doi:10.1016/0166-4972(88)90052-1

Carmel, D., Uziel, E., Guy, I., Mass, Y., Roitman, H., 2012. Folksonomy-Based Term Extraction for Word Cloud Generation. ACM Trans Intell Syst Technol 3, 60:160:20. doi:10.1145/2337542.2337545

Clarysse, B., Wright, M., Bruneel, J., Mahajan, A., 2014. Creating value in ecosystems: Crossing the chasm between knowledge and business ecosystems. Res. Policy 43, 1164-1176. doi:10.1016/j.respol.2014.04.014

Cumming, D.J., Leboeuf, G., Schwienbacher, A., 2014. Crowdfunding Models: Keep-itAll vs. All-or-Nothing.

De Buysere, K., Gajda, O., Kleverlaan, R., Marom, D., Klaes, M., 2012. A framework for European crowdfunding. Eur. Crowdfunding Netw. ECN Available Www Eur. Orgeuropean Crowdfundingframework.

Ekman, P., 1992. An argument for basic emotions. Cogn. Emot. doi:10.1080/02699939208411068

Ekman, P., Levenson, R.W., Friesen, W. V, 1983. Autonomic nervous system activity distinguishes among emotions. Science 221, 1208-1210. doi:10.1126/science. 6612338

Erkinheimo, P., Kärkkäinen, H., Jussila, J., 2016. CROWDSOURCING FOR VALUE CREATION IN LEAN START-UPS, in: Open Innovation: A Multifaceted Perspective. WORLD SCIENTIFIC, pp. 423-441. doi:10.1142/9789814719186 0017

Feldmann, N., Gimpel, H., Muller, M., Geyer, W., 2014. IDEA ASSESSMENT VIA ENTERPRISE CROWDFUNDING: AN EMPIRICAL ANALYSIS OF DECISION-MAKING STYLES.

Fisk, R.P., Patrício, L., Ordanini, A., Miceli, L., Pizzetti, M., Parasuraman, A., 2011. Crowd-funding: transforming customers into investors through innovative service platforms. J. Serv. Manag. 22, 443-470.

Frydrych, D., Bock, A.J., Kinder, T., Koeck, B., 2014. Exploring entrepreneurial legitimacy in reward-based crowdfunding. Venture Cap. 16, 247-269.

Gerber, E.M., Hui, J.S., Kuo, P.-Y., 2012. Crowdfunding: Why people are motivated to post and fund projects on crowdfunding platforms. Proc Int. Workshop ... 10. doi:http://dx.doi.org/10.1145/2530540

Gierczak, M., Bretschneider, U., Leimeister, J.M., 2014. Is all that Glitters Gold? Exploring The Effects of Perceived Risk on Backing Behavior in Reward-based Crowdfunding.

Greenberg, M.D., Gerber, E.M., 2014. Learning to fail: experiencing public failure online through crowdfunding. ACM, pp. 581-590.

Haas, P., Blohm, I., Leimeister, J.M., 2014. An Empirical Taxonomy of Crowdfunding Intermediaries. 
Menon et al.

Herkman, E., Brussee, R., 2012. Crowdfunding and Online Social networks. mmu.ac.uk $1-22$.

Hisricha, R.D., Peters, M.P., Shepherd, D.A., Bieto, E., Ollè, M., Planellas, M., 2005. Entrepreneurship : emprendedores. McGraw-Hill/Interamericana, Madrid.

Huhtamäki, J., Lasrado, L., Menon, K., Kärkkäinen, H., Jussila, J., 2015. Approach for Investigating Crowdfunding Campaigns with Platform Data: Case Indiegogo, in: Proceedings of the 19th International Academic Mindtrek Conference: Academic Mindtrek '15. pp. 183-190. doi:10.1145/2818187.2818289

Hussain, A., Vatrapu, R., 2014a. Social Data Analytics Tool: Design, Development, and Demonstrative Case Studies. IEEE, pp. 414-417.

Hussain, A., Vatrapu, R., 2014b. Social data analytics tool (sodato). Springer, pp. 368372.

Hussain, A., Vatrapu, R., Hardt, D., Jaffari, Z., 2014. Social data analytics tool: A demonstrative case study of methodology and software. Anal. Soc. Media Data Web Netw. MC Rachel Gibson Ward Eds Palgrave Macmillan 3, London.

Iansiti, M., Levien, R., 2004. Strategy as Ecology. Harv. Bus. Rev. doi:10.1108/eb025570

Jussila, J., Menon, K., Mukkamala, R.R., Lasrado, L.A., Hussain, A., Vatrapu, R., Kärkkäinen, H., Huhtamäki, J., 2016. Crowdfunding in the Development of Social Media Fanbase - Case Study of Two Competing Ecosystems. pp. 44954504. doi:10.1109/HICSS.2016.559

Lasrado, L.A., 2013. Crowdfunding in Finland-A new Alterantive Disruptive Funding Instrument for Business, Master of Science Thesis. TAMPERE UNIVERSITY OF TECHNOLOGY.

Lasrado, L.A., Lugmayr, A., 2013. Crowdfunding in Finland: A New Alternative Disruptive Funding Instrument for Businesses. ACM, p. 194.

Lavidge, R.J., Steiner, G. a. (Gary A., 1961. A Model For Predictive Measurements of Advertising Effectiveness. J. Mark. 25, 59-62. doi:10.2307/1248516

Lu, C.-T., Xie, S., Kong, X., Yu, P.S., 2014. Inferring the Impacts of Social Media on Crowdfunding, in: WSDM '14. ACM, New York, NY, USA, pp. 573-582. doi: $10.1145 / 2556195.2556251$

Macht, S.A., Weatherston, J., 2014. The Benefits of Online Crowdfunding for FundSeeking Business Ventures. Strateg. Change 23, 1-14. doi:10.1002/jsc. 1955

MacKinlay, A.C., 1997. Event Studies in Economics and Finance. J. Econ. Lit. 35, 1339.

McWilliams, A., Siegel, D., 1997. Event Studies In Management Research: Theoretical And Empirical Issues. Acad. Manage. J. 40, 626-657. doi:10.2307/257056

Mizruchi, M.S., 1994. Social network analysis: Recent achievements and current controversies. Acta Sociol. 37, 329-343.

Mollick, E., 2014. The dynamics of crowdfunding: An exploratory study. J. Bus. Ventur. 29, 1-16.

Mollick, E., 2012. The dynamics of crowdfunding: Determinants of success and failure. SSRN scholarly paper. Soc. Sci. Res. Netw. Rochester NY.

Moore, J.F., 1993. A New Ecology of Competition Harvard Business Review. Harv. Bus. Rev. 71(3), 75-86.

Moran, E.F., 1990. The Ecosystem Approach in Anthropology: From Concept to Practice 476, University of Michigan Press, 1990.

Mukkamala, R.R., Hussain, A., Vatrapu, R., 2014. Fuzzy-Set Based Sentiment Analysis of Big Social Data. IEEE, pp. 71-80.

Mukkamala, R.R., Sorensen, J.I., Hussain, A., Vatrapu, R., 2015. Detecting Corporate Social Media Crises on Facebook Using Social Set Analysis, in: Proceedings - 
Analysing the Role of Crowdfunding in Entrepreneurial Ecosystems: A Social Media Event Study of Two Competing Product Launches

2015 IEEE International Congress on Big Data, BigData Congress 2015. pp. 745-748. doi:10.1109/BigDataCongress.2015.123

Mukkamala, R.R., Sorensen, J.I., Hussain, A., Vatrapu, R., 2015. Social set analysis of corporate social media crises on Facebook, in: IEEE 19th International Enterprise Distributed Object Computing Conference (EDOC). pp. 112-121.

Müllerleile, T., Joenssen, D.W., 2015. Key Success-Determinants of Crowdfunded Projects: An Exploratory Analysis, in: Lausen, B., Krolak-Schwerdt, S., Böhmer, M. (Eds.), Studies in Classification, Data Analysis, and Knowledge Organization. Springer Berlin Heidelberg, pp. 271-281.

Ortony, A., Turner, T.J., 1990. What's basic about basic emotions? Psychol. Rev. 97, 315-331. doi:10.1037/0033-295X.97.3.315

Posegga, O., Zylka, M.P., Fischbach, K., 2015. Collective Dynamics of Crowdfunding Networks. IEEE, pp. 3258-3267.

Quero, M.J., Kelleher, C., Ventura, R., 2014. Value-in-context in Crowd-funding ecosystems: how context frames value co-creation.

Ray, M.L., Sawyer, A., Rothschild, M.L., Heeler, R.M., Strong, E.C., Reed, J.B., 1973. Marketing communication and the hierarchy of effects. New Models Mass Commun. Res. 2, 147-176.

Ritala, P., Hurmelinna-Laukkanen, P., 2013. Incremental and radical innovation in coopetition-The role of absorptive capacity and appropriability. J. Prod. Innov. Manag. 30, 154-169.

Ritala, P., Hurmelinna-Laukkanen, P., 2009. What's in it for me? Creating and appropriating value in innovation-related coopetition. Technovation 29, 819828.

Rodrigues, R.F.F., 2015. Factors influencing consumer decision in crowdfunding. Dissertation, Escola de Administração de Empresas de São Paulo, São Paulo (Doctoral dissertation).

Rubens, N., Still, K., Huhtamaki, J., Russell, M.G., 2011. A network analysis of investment firms as resource routers in Chinese innovation ecosystem. J. Softw. 6, 1737-1745.

Russell, M.G., Huhtamaki, J., Still, K., Rubens, N., Basole, R.C., 2015. Relational Capital for Shared Vision in Innovation Ecosystems. Triple Helix J. Univ.-Ind.Gov. Innov. Entrep. THJI. 29(2), 109-123.

Russell, M.G., Still, K., Huhtamäki, J., Yu, C., Rubens, N., 2011. Transforming innovation ecosystems through shared vision and network orchestration. Proc. Triple Helix IX Conf.

Schulz, M., Haas, P., Schulthess, K., Blohm, I., Leimeister, J.M., 2015. How Idea Creativity and Hedonic Value Influence Project Success in Crowdfunding.

Thies, F., Wessel, M., Benlian, A., 2014. Understanding the Dynamic Interplay of Social Buzz and Contribution Behavior within and between Online Platforms Evidence from Crowdfunding. ICIS 2014 Proc.

Thomas, L., Sharapov, D., Autio, E., 2017. Linking Entrepreneurial and Innovation Ecosystems: the Case of Appcampus, in: Entrepreneurial Ecosystems and the Diffusion of Startups. Cheltenham, UK, Edward Elgar Publishing. p. 208.

Thomas, L.D., Autio, E., Gann, D.M., 2014. Architectural leverage: putting platforms in context. Acad. Manag. Perspect. 28, 198-219.

Valkokari, K., 2015. Business , Innovation, and Knowledge Ecosystems: How They Differ and How to Survive and Thrive within Them. Technol. Innov. Manag. Rev. 5, 17-24. 
Menon et al.

Vargo, S.L., Wieland, H., Akaka, M.A., 2015. Innovation through institutionalization: A service ecosystems perspective. Ind. Mark. Manag. 44(2015), 63-72.

Vatrapu, R., Mukkamala, R.R., Hussain, A., 2014. Towards a Set Theoretical Approach to Big Social Data Analytics: Concepts, Methods, Tools, and Empirical Findings.

Wu, S.., Wang, B.., Li, Y.., 2015. How to attract the crowd in crowdfunding? Int. J. Entrep. Small Bus. 24, 322-334. doi:10.1504/IJESB.2015.067465

Yang, Y., Liu, X., 1999. A re-examination of text categorization methods, in: Proceedings of the 22nd Annual International ACM SIGIR Conference on Research and Development in Information Retrieval - SIGIR '99. ACM Press, New York, New York, USA, pp. 42-49. doi:10.1145/312624.312647

Zhang, H., Li, D., 2007. Naïve Bayes Text Classifier, in: 2007 IEEE International Conference on Granular Computing (GRC 2007). IEEE, pp. 708-708. doi: $10.1109 /$ GrC.2007.40

Zheng, H., Wan, N., Chen, D., Wang, T., 2014. Antecedents of Project Implementation Success in Crowdfunding. 18th PACIS Chengdu China 1-13.

Zvilichovsky, D., Inbar, Y., Barzilay, O., 2014. Playing both sides of the market: success and reciprocity on crowdfunding platforms. Available SSRN 2304101. 